\title{
Evaluating Temperature and Fuel Stratification for Heat-Release Rate Control in a Reactivity-Controlled Compression-Ignition Engine using Optical Diagnostics and Chemical Kinetics Modeling
}

\author{
Sage L. Kokjohn", ${ }^{\mathrm{a},}$, Mark P.B. Musculus ${ }^{\mathrm{b}}$, Rolf D. Reitz \\ ${ }^{a}$ University of Wisconsin - Madison, Engineering Research Building, 1500 Engineering Dr., Madison, WI 53706 \\ ${ }^{b}$ Combustion Research Facility, Sandia National Laboratories, Livermore, CA 94550
}

\begin{abstract}
The combustion process in a dual-fuel, reactivity-controlled compression-ignition (RCCI) engine is investigated using a combination of optical diagnostics and chemical kinetics modeling to explain the role of equivalence ratio, temperature, and fuel reactivity stratification for heatrelease rate control. An optically accessible engine is operated in the RCCI combustion mode using gasoline primary reference fuels (PRF). A well-mixed charge of iso-octane ( $\mathrm{PRF}=100)$ is created by injecting fuel into the engine cylinder during the intake stroke using a gasoline-type direct injector. Later in the cycle, $\mathrm{n}$-heptane $(\mathrm{PRF}=0)$ is delivered through a centrally mounted diesel-type common-rail injector. This injection strategy generates stratification in equivalence ratio, fuel blend, and temperature. The first part of this study uses a high-speed camera to image the injection events and record high-temperature combustion chemiluminescence. The chemiluminescence imaging showed that, at the operating condition studied in the present work, mixtures in the squish region ignite first, and the reaction zone proceeds inward toward the center of the combustion chamber. The second part of this study investigates the charge
\end{abstract}

\footnotetext{
* Corresponding author

Email address: kokjohn@wisc.edu
} 
preparation of the RCCI strategy using planar laser-induced fluorescence (PLIF) of a fuel tracer under non-reacting conditions to quantify fuel concentration distributions prior to ignition. The fuel-tracer PLIF data show that the combustion event proceeds down gradients in the n-heptane distribution. The third part of the study uses chemical kinetics modeling over a range of mixtures spanning the distributions observed from the fuel-tracer fluorescence imaging to isolate the roles

of temperature, equivalence ratio, and PRF number stratification. The simulations predict that PRF number stratification is the dominant factor controlling the ignition location and growth rate of the reaction zone. Equivalence ratio has a smaller, but still significant, influence. Temperature stratification had a negligible influence due to the NTC behavior of the PRF mixtures.

\section{Keywords}

RCCI, reactivity stratification, optical diagnostics, chemical kinetics modeling

\section{Definition of Acronyms}

AHRR Apparent heat release rate

ATDC After top dead center

BDC Bottom dead center

CCD Charge coupled device

CFD Computational fluid dynamics

CMOS Complementary metal oxide semiconductor

CR Common-rail

DI Direct injected

DOE Design of Experiments

FOV Field of View

FTIR Fourier-transform infrared

GDI Gasoline direct injection

HCCI Homogeneous charge compression ignition

HPLC High performance liquid chromatography

HSC High speed camera

IMEP Indicated mean effective pressure

IR Infrared

LIF Laser induced fluorescence

LWP Long wave pass

NTC Negative Temperature Coefficient 


$\begin{array}{ll}\text { PCI } & \text { Premixed compression ignition } \\ \text { PLIF } & \text { Planar laser-induced fluorescence } \\ \text { PRF } & \text { Primary reference fuel } \\ \text { RCCI } & \text { Reactivity controlled compression ignition } \\ \text { ROI } & \text { Rate of Injection } \\ \text { SNR } & \text { Signal-to-noise ratio } \\ \text { SOI } & \text { Start of Injection } \\ \text { SWP } & \text { Short wave pass } \\ \text { TDC } & \text { Top dead center } \\ \text { UV } & \text { Ultra violet }\end{array}$




\section{Introduction}

Highly premixed compression ignition (PCI) strategies, e.g., homogenous charge compression ignition (HCCI), offer attractive emissions and performance characteristics (i.e., high efficiency and low NOx and soot emissions) $[\mathbf{1 , 2 , 3 , 4 ]}$. Although promising, these operating strategies are generally confined to low engine loads due to difficulties controlling the heatrelease rate and lack of an adequate combustion phasing control mechanism. Recently, Sjöberg et al. [5] proposed that partial fuel-stratification may be a promising method to control the heatrelease rate for HCCI engines. Additionally, Dec et al. [6,7] showed that harnessing natural thermal stratification is a potential method to control HCCI heat-release rates and increase the HCCI operating range. Both thermal and equivalence ratio stratification introduce nonuniformities in the auto-ignition characteristics of the charge. These non-uniformities result in a staged ignition event, which tends to reduce the peak heat-release rate.

Kokjohn et al. [8] proposed blending two fuels with different auto-ignition characteristics inside the combustion chamber to artificially generate non-uniformities in the auto-ignition characteristics of the charge. Using metal engine experiments, Hanson et al. [9] and Kokjohn et al. [10] showed that compared to single-fuel strategies, stratifying the fuel reactivity via incylinder blending of two fuels of differing reactivity improves the control over the heat-release rate and thereby allows extension of PCI combustion to higher engine loads. Consequently, they termed this alternative combustion mode "reactivity controlled compression ignition," or RCCI. Further, the metal engine experiments have shown that RCCI combustion can achieve gross indicated efficiencies over 50 percent for a wide range of operating conditions while meeting current, heavy-duty, on-highway NOx and soot emissions limits without exhaust-gas 
afterteatment ${ }^{1}$. The high efficiency, compared to conventional diesel combustion, is primarily due to reductions in heat transfer losses by avoiding high-temperature regions [11]. Although these metal engine experiments are useful to understand emissions and performance tradeoffs, they do not reveal details of the dominant in-cylinder processes controlling RCCI combustion.

In an attempt to improve the fundamental understanding of RCCI combustion, Splitter et al. [12] used in-cylinder Fourier-transform infrared (FTIR) spectroscopy to investigate the evolution of the RCCI combustion process. FTIR spectra were acquired at two locations, to provide a degree of spatial resolution, and were indexed to engine crank-angle to give cycleaveraged, crank-angle-resolved in-cylinder spectroscopy. Their results suggested that the RCCI combustion process proceeded at different rates in different locations of the cylinder. However, their measurements were restricted by the limited optical access of their engine. Additionally, several studies have used detailed CFD modeling (e.g., Kokjohn et al. [8]) with reduced kinetics mechanisms to investigate RCCI combustion. The CFD modeling predicted that nonuniformities in the auto-ignition characteristics of the charge (i.e., fuel reactivity), as created by in-cylinder fuel blending, control the heat-release rate.

In the present study, RCCI combustion is investigated in a heavy-duty, single cylinder, optically accessible research engine using a combination of high-speed chemiluminescence imaging and fuel-tracer planar laser-induced fluorescence (PLIF). There are three main objectives. The first objective is to gain insight into the dominant mixing and ignition processes controlling the RCCI combustion event through observation of ignition locations and key features of the reaction zone growth. The second is to evaluate the dependence of the reaction-

\footnotetext{
${ }^{1}$ Note that a diesel oxidation catalyst would still be required to control relatively high hydrocarbon and carbon monoxide emissions.
} 
zone growth on fuel reactivity stratification. The third objective is to isolate the roles of temperature, equivalence ratio, and fuel blend stratification.

\section{Experimental Setup}

\subsection{Engine Specifications}

The single-cylinder, direct-injection, 4-stroke optically accessible research engine of this study is based on a Cummins N14 production diesel engine. Table 1 gives the engine specifications and Figure 1 shows a schematic of the combustion chamber. The research engine is typical of a heavy-duty diesel engine with a $13.97 \mathrm{~cm}$ bore and $15.24 \mathrm{~cm}$ stroke giving a displacement of $2.34 \mathrm{~L}$ per cylinder. The intake port geometry of the production engine, which has a steady state (i.e., measured on a flow-bench) swirl ratio of 0.5 [13], is preserved in the research engine. To allow optical access, the engine is equipped with an extended piston and the stock metal piston bowl has been replaced with a flat fused silica piston crown window. Further, one of the two exhaust valves has been replaced with a window, and a periscope mirror in the rocker box provides a view through that window of a portion of the squish region (i.e., the region above the piston bowl-rim). Four windows are also located around the upper portion of the cylinder wall to allow cross-optical access for laser-based diagnostics. A complete description of the engine development is available in Ref. [14].

\subsubsection{Fuel Injection Systems}

RCCI combustion is achieved by using in-cylinder blending of two fuels with different reactivities (i.e., auto-ignition characteristics), such as gasoline and diesel fuels. Multicomponent gasoline and diesel fuels contain molecules that fluoresce when illuminated by ultraviolet light, which would interfere with the toluene fuel-tracer fluorescence diagnostic (described in the Optical Diagnostics section). Hence, to facilitate the fuel-tracer measurements, 
the engine is fueled with purified gasoline primary reference fuel (PRF) components (i.e., nheptane and iso-octane) because they display insignificant fluorescence interference. A charge of high-purity (99\% or better) iso-octane is delivered using a gasoline direct injection (GDI) system. The GDI injector is mounted in a metal blank in place of one of the optical access windows formerly located in the cylinder wall (see Figure 2). The specifications of the GDI injector are provided in Table 2. The GDI has a 7-hole, asymmetric tip, with all seven holes located on one hemisphere of the injector. This hole layout avoids fuel impingement on the cylinder head for this wall-mounted injector (i.e., perpendicular to the axis of the piston). Figure 3 shows a drawing of the GDI spray pattern. A Newport Scientific high-pressure diaphragm pump pressurizes the HPLC-grade n-heptane to 600 bar and a Cummins XPI high-pressure, electronically-controlled, common-rail (CR) fuel injector with specifications given in Table 3 delivers the n-heptane directly into the combustion chamber. For the present study, an 8-hole mini-sac tip is installed in the injector. Each hole of this tip has a nominal orifice diameter of 140 microns. The nozzle has an included angle of $152^{\circ}\left(14^{\circ}\right.$ downward from the fire deck, i.e., the bottom surface of the cylinder head exposed to the combustion chamber). Finally, to minimize thermal loading, the engine is only fired 1 out of 10 cycles and the engine speed was maintained by an electric dynamometer during non-fired cycles.

\subsubsection{Operating condition}

Table 4 shows the engine operating conditions. For all tests, the engine speed is 1200 $\mathrm{rev} / \mathrm{min}$ and a gross indicated mean effective pressure (IMEP) is $4.2 \mathrm{bar}$. This light-load condition was chosen to avoid damaging the large piston crown window for some conditions explored with high heat-release rates. With the intent of creating a well-mixed charge of isooctane, $41 \mathrm{mg}$ of iso-octane is delivered through the GDI injector at $-240^{\circ}$ ATDC (during the intake stroke) at an injection pressure of 100 bar. The n-heptane is delivered through the 
common-rail injector at a pressure of 600 bar using a split-injection with a first pulse beginning at $-57^{\circ}$ ATDC and a second pulse beginning at $-37^{\circ}$ ATDC. These injection timings are the same as previous RCCI metal engine experiments (e.g., Kokjohn et al. [11]). The injection strategy was developed using detailed computational fluid dynamics modeling coupled with a genetic algorithm. Further details can be found in Kokjohn et al. [8]. The total injected mass of nheptane is $21 \mathrm{mg}$ and approximately $60 \%$ of the n-heptane is delivered in the first injection (i.e., at $-57^{\circ}$ ATDC). The engine is operated without any dilution (i.e., the inlet is air with an oxygen concentration of approximately $21 \%$ by volume, and because of skip-firing the residual gas fraction is essentially zero) and the intake pressure was set to slightly above atmospheric at 1.1 bar absolute, and the intake temperature is $93^{\circ} \mathrm{C}$. The resulting density and temperature of the air charge (excluding injected fuel) at TDC, as estimated assuming a polytropic compression with an exponent of 1.35 for this $10.75: 1$ compression-ratio engine, is $11.2 \mathrm{~kg} / \mathrm{m}^{3}$ and $835 \mathrm{~K}$, respectively.

\subsection{Conventional Data acquisition}

Cylinder pressure is measured with an AVL QC43D piezoelectric transducer at $14^{\circ}$ crank angle increments and the measurements were set to match (pegged to) the intake pressure at bottom dead center (BDC) of the intake stroke as measured by a strain-gage-type transducer. The apparent heat-release rate (AHRR) is calculated from the measured pressure data using the standard first-law analysis (e.g., Heywood [15]) with constant gas properties. Prior to calculating the AHRR, the cylinder pressure data are smoothed using a Fourier series low-pass filter with a Gaussian roll-off function having a transmission of $100 \%$ from 0 to $800 \mathrm{~Hz}$ and dropping to $1 \%$ at $3360 \mathrm{~Hz}$. 


\subsection{Optical Diagnostics}

\subsubsection{High Speed Combustion Luminosity Imaging}

Figure 2 (a) shows the experimental setup for high-speed combustion luminosity. Crankangle-resolved combustion luminosity is imaged by an unintensified Phantom 7.1 complementary metal oxide semiconductor (CMOS) high-speed camera (HSC) equipped with a 50-mm glass Nikkor lens with the aperture fully open (f/1.2). Because a glass lens was used, $\mathrm{OH}^{*}$ does not contribute to the recorded combustion luminosity. High-speed combustion luminosity is recorded in two locations: 1) with the camera viewing upward through the piston crown window and 2) with the camera viewing downward into the squish region through the cylinder head window. Furthermore, a combination of a 500-nm short-wave-pass (SWP) filter and a BG39 colored-glass filter reject long-wavelength (green through IR) soot luminosity (if present). The recorded luminosity is likely chemiluminescence from $\mathrm{CH}_{2} \mathrm{O}^{*}, \mathrm{HCO}^{*}, \mathrm{CH}^{*}$, and $\mathrm{CO}_{2}{ }^{*}$, broadband emission from the $\mathrm{CO}$ continuum [16,17], and well after ignition, possibly some soot luminosity that is not entirely rejected by the BG39 filter. The HSC images are acquired with a resolution of $512 \times 512$ pixels and the exposure time for each frame is $125 \mu \mathrm{s}$. The long exposure time relative to engine flow and chemical timescales is required to collect sufficient imaging signal with the non-intensified HSC used in this study.

\subsubsection{Fuel Tracer Fluorescence}

Fuel-vapor concentrations are quantified using toluene fuel-tracer fluorescence. The toluene fuel-tracer fluorescence is measured at the same thermodynamic conditions as those presented in Table 4; however, to avoid complications from oxygen quenching of the toluene fluorescence, the engine intake was supplied with 100\% nitrogen. HPLC n-heptane doped with $1 \%$ toluene is used for quantitative fuel distribution measurements. Previous work (e.g., Genzale et al. [13]) showed that this toluene concentration provided a good balance between signal 
strength and attenuation of the laser light. The same toluene-doped n-heptane is used in both fuel systems (for the non-combusting conditions) to avoid uncertainties in the toluene fluorescence yield in different solvents. Superposition of fuel concentration measurements from separate experiments using one injector at a time provides quantitative in-cylinder distributions of the two fuels from the two injectors.

Figure 2 (b) shows the laser sheet and imaging setup for the toluene fuel-tracer fluorescence measurements. The toluene fluorescence was excited by the 266-nm output of a frequency-quadrupled Nd:YAG laser. The laser beam is formed into a thin sheet (less than $1 \mathrm{~mm}$ thick) using a combination of a negative cylindrical lens $(f=-50 \mathrm{~mm})$ and positive planospherical lens ( $\mathrm{f}=500 \mathrm{~mm}$ ). The low-intensity tails on either end of the sheet are clipped so that only the center of the beam, with relatively uniform intensity, entered the engine. After being clipped, the sheet passing through the window is approximately $31 \mathrm{~mm}$ wide with a remaining energy of $26 \mathrm{~mJ}$ per pulse.

Images are acquired at two laser-sheet heights. Figure 4 shows a schematic of the two laser-sheet setups. Early-cycle images of the mixing process (from $-50^{\circ}$ ATDC to $-21^{\circ}$ ATDC) are acquired with the laser sheet located $10 \mathrm{~mm}$ below the firedeck ${ }^{2}$ as indicated in Figure 4 (a). Notice that these images were acquired with the camera (discussed below) viewing downward into the squish region (i.e., above the piston bowl rim). For as much of the cycle as possible, the piston bowl-rim is rotated with the cut-out on the opposite side of the cylinder relative to the imaging port, so that the flows are representative of a realistic engine geometry in the imaged region. At $-21^{\circ}$ ATDC, the piston bowl-rim intersects the laser sheet, such that imaging above

\footnotetext{
${ }^{2}$ The rounded corners of the cross-optical-access window begin to obstruct the full width of the laser sheet at elevations higher than $10 \mathrm{~mm}$ below the firedeck; thus, this is effectively the highest imaging location possible using the full width of the laser sheet.
} 
the piston bowl-rim is not possible. To allow imaging of the region above the piston when it is near TDC (from $-21^{\circ}$ ATDC to $+21^{\circ}$ ATDC), the piston bowl-rim cutout is rotated $180^{\circ}$ into the camera field of view. Images after $-21^{\circ}$ ATDC are acquired inside of this cutout as indicated in Figure 4 (b) and with a laser sheet height of $13 \mathrm{~mm}$ below the firedeck. The flow-field is certainly affected by the cut-out; however, because the n-heptane injection occurs early in the cycle and is not confined to the piston bowl region (as in conventional diesel combustion), the impact of the cut-out is expected to be small. The small impact of the cut-out is verified by comparing fuel tracer fluorescence images acquired at $-21^{\circ}$ ATDC in and out of the cut-out (cf. Section 3.3).

A blue-optimized, intensified CCD camera (Princeton Instruments PI-MAX3:1024i SB) with a $55 \mathrm{~mm} \mathrm{f} / 3.5 \mathrm{UV}$ lens with the aperture fully open images the resulting florescence viewing downward through the cylinder-head window (see Figure 2 (b) and Figure 4). A WG295 long-wave-pass (LWP) filter helps to isolate the toluene fluorescence $(265-330 \mathrm{~nm})$ from scattered laser light. Additionally, a UG5 UV-bandpass filter (passband in the range of 220 to $400 \mathrm{~nm}$ ) blocks red-shifted fluorescence from motor oil and other sources.

Conversion of the raw toluene PLIF images to fuel-vapor concentration measurements requires careful calibration of the temperature dependence of the fluorescence quantum yield and absorption cross section, and potential pressure dependence due to line broadening and collisional quenching with $\mathrm{N}_{2}$ and fuel [18]. Full details of the diagnostic can be found in Musculus et al. [19]; thus, only the three main steps are discussed here.

First, the temperature and pressure sensitivity of the PLIF signal is evaluated under wellmixed conditions over a range of temperatures and pressures. A known quantity (39 mg/cycle) of toluene-doped fuel is injected early in the intake stroke to create a well-mixed charge. The 
temperature and pressure are varied by changing the intake temperature, changing the intake pressure, and by recording images at several different crank angles during the compression stroke (i.e., changing the amount of compression at the time of image acquisition). Temperature calibration is performed at 11 different crank angles during the compression stroke and two intake temperatures $\left(90^{\circ} \mathrm{C}\right.$ and $170{ }^{\circ} \mathrm{C}$ ) at a fixed intake flowrate of $23 \mathrm{~g} / \mathrm{s}$. The resulting temperature range covered is $540 \mathrm{~K}$ to $934 \mathrm{~K}$. The temperature was calculated using adiabatic compression according to the measured pressure trace. The compression calculation accounts for variable specific heats and represents the adiabatic "core" of the charge (away from the boundary layer gases). Figure 5 shows the relative toluene fluorescence yield evaluated over a range of incylinder temperatures from $550 \mathrm{~K}$ to $940 \mathrm{~K}$ during the compression stroke, corrected for changing charge density according to the geometric cylinder volume. No correction for the changing pressure is applied. Following the work of Musculus et al. [19], an offset exponential is fit to the data and serves as a temperature calibration curve. The temperature calibration curve is

$$
I_{\text {rel }}=1+10^{\frac{900-T}{256}}
$$

where $I_{r e l}$ is the relative florescence intensity and $T$ is the temperature.

Similar to the temperature dependence, the pressure dependence is evaluated over a range of conditions. Pressure calibration is performed at two crank angles $\left(-30^{\circ}\right.$ ATDC and TDC) and two intake temperatures $\left(90^{\circ} \mathrm{C}\right.$ and $\left.170{ }^{\circ} \mathrm{C}\right)$. At each crank angle and intake temperature combination, the flowrate is swept from $13 \mathrm{~g} / \mathrm{s}$ to $28 \mathrm{~g} / \mathrm{s}$ to vary the compression stroke pressure at a nearly constant temperature. Consistent with the findings of Musculus et al. [19], the toluene PLIF signal is independent of pressure after the temperature corrections were applied.

Second, fuel-vapor concentrations are measured for separate injections from both the common-rail and GDI fuel systems. At each crank angle of interest, images are acquired in sets 
of four. Between each image, the engine is motored (without supplying fuel) for 9 cycles, which scavenges residual fuel from the combustion chamber. The first image has no fuel injection and records background fluorescence interference-likely due at least in part to residual lubrication oil excited by scattered laser light. The second image provides a flat-field calibration at a known toluene/fuel concentration. The third and fourth images record fluorescence from the fuel injected through the GDI only and common-rail injector only, respectively. This four-image sequence is repeated 40 times at each crank angle of interest. After the image-acquisition sequence, the optics are cleaned and the procedure is repeated for the next crank angle.

After subtracting the background image, a single-point calibration method is used and a linear relationship between the PLIF signal and tracer concentration is assumed. That is, the fuel distribution is calculated by normalizing the fluorescence intensity by the flat-field calibration image as

$$
n_{\text {data }}=n_{\text {calibration }} \frac{I_{\text {data }}}{I_{\text {calibration }}},
$$

where $n_{\text {data }}$ is the local fuel-vapor molar density and $n_{\text {calibration }}$ is fuel-vapor molar density of the calibration image calculated from the known fuel mass and in-cylinder volume, $I_{\text {data }}$ is the local fluorescence intensity of the data image, and $I_{\text {calibration }}$ is the local fluorescence intensity of the calibration image. In Eq. 2, $I_{\text {data }}$ and $I_{\text {calibration }}$ are corrected to account for the temperature sensitivity of toluene fluorescence using the temperature calibration of Eq. 1.

Third, an iterative procedure is used to calculate the temperature and fuel concentration at each crank angle using the temperature and concentration calibrations from the first two steps. Figure 6 shows a flow diagram of the iterative procedure. The temperature and fuel distribution are calculated by first assuming a uniform temperature distribution at the image acquisition time to obtain an estimate of the fuel concentration distribution using the single-point calibration from 
step two. The initial estimate of the uniform temperature at the image acquisition time is calculated by numeric integration assuming adiabatic compression according to the measured pressure trace. The compression calculation accounts for variable specific heats and represents the adiabatic "core" of the charge (away from the boundary layer gases). The temperature field at the image acquisition time was recomputed to account for evaporative cooling and the difference in specific heats of $N_{2}$ and fuel in three steps.

1) Fuel is assumed to be injected and fully mixed to the estimated local fuel concentration at the SOI timing. The temperature of the resulting mixture is calculated assuming isenthalpic vaporization (adiabatic mixing) starting from liquid fuel at the coolant temperature and compression-heated $N_{2}$ at the SOI crank angle, and ending with a uniform-temperature mixture of vapor fuel and $N_{2}$ for each pixel.

2) The charge of $N_{2}$ and vapor fuel is then compressed from the SOI crank angle to the image acquisition crank angle assuming that the fuel distribution remains unchanged. Although the real fuel distribution is not actually instantaneously mixed, nor is it unchanging during the compression stroke, this simplification in the calculation provides a method to account for the temperature distribution resulting from fuel vaporization and the different heat capacities of $N_{2}$ and n-heptane.

3) With the new temperature, the fuel concentration estimate is updated according to Equations 1 and 2 and the iteration is repeated using the new fuel distribution. This iterative procedure is looped until the average fuel concentration changes by less than $0.02 \%$ per iteration.

To improve the signal-to-noise ratio (SNR) of the images, the fuel distributions of the GDI and common-rail injections are ensemble averaged over 40 images. The average fuel- 
distribution maps are generated by combining the GDI and common-rail fuel concentration measurements. Of particular interest to this study are the relative concentrations of fuel from the GDI and common-rail fuel streams. Thus, the PRF number is defined as

$$
P R F=100 \frac{m_{G D I} / \rho_{\text {iso-octane }}}{m_{G D I} / \rho_{\text {iso-octane }}+m_{C R} / \rho_{\text {n-heptane }}},
$$

where the $m_{G D I}$ is the measured vapor-fuel mass from the GDI images, corrected for the difference in molecular weight of iso-octane and n-heptane, $m_{C R}$ is the mass of n-heptane measured from the common-rail (CR) injection images, and $\rho_{\text {iso-octane }}$ and $\rho_{n \text {-heptane }}$ are the densities of liquid iso-octane and n-heptane, respectively. This definition of PRF number is equivalent to a volume percent (by liquid) of iso-octane in the fuel blend for each pixel. This definition of PRF number is consistent with the general definition of PRF number used in fuel octane testing. Thus, in the imaging, the PRF number can be interpreted as a local octane number.

To use the fuel distribution measurements to explain the differences in the combustion characteristics, the uncertainty of the measurement must be addressed. For the present study, the precision of the measurement is of more interest than the absolute accuracy. That is, the gradients in PRF number and equivalence ratio are of more interest than the absolute value of PRF or equivalence ratio. The precision of the measurement is estimated using the calibration images. Each single-shot calibration image is processed to calculate a $95 \%$ confidence interval on the mean fuel concentration of each pixel. The processing includes applying a $5 \times 5$ pixel filter. The filter removes much of the fine-scale noise, but it has virtually no effect on the effective image resolution, since 5 pixels corresponds to $0.25 \mathrm{~mm}$, which is approximately one quarter of the average laser sheet thickness. The confidence intervals at each pixel are averaged to give a single number representing the relative error in each image. This error accounts for shot-to-shot 
variations in the mixture distribution, shot-to-shot variations in the laser sheet intensity profile, shot-to-shot variations in the injected fuel mass, and camera/shot noise. The equivalence ratio and PRF images are calculated by summing the GDI and common-rail images (see Eq. 3); therefore, the combined uncorrelated precision error for these images can be calculated by summing the error in quadrature. The resulting relative error in the equivalence ratio and PRF images is approximately 7\%. For example, a PRF 50 mixture with an equivalence ratio of 0.5 has error bounds of $\pm 4 \mathrm{PRF}$ and $\pm 0.04 \phi$. Recall that the $7 \%$ relative error corresponds to a filtering size of $0.25 \mathrm{~mm}$ and is a conservative estimate of the error. The main goal of the present work is to relate large-scale gradients in equivalence ratio and PRF number to the reaction zone evolution. For these purposes, little information is lost by applying a larger filter, while the uncertainty can be greatly reduced. For example, if the filtering size is increased to $1 \mathrm{~mm}$ (near the average laser sheet thickness), the relative uncertainty decreases to $3.4 \%$. The variations in equivalence ratio or PRF number across the images reported here exceed this uncertainty, and are therefore statistically significant for 10 -mm or larger structures.

\section{Results}

\subsection{Cylinder Pressure and Heat Release Rate}

Figure 7 shows the measured cylinder pressure, common-rail fuel injector rate of injection (ROI), and apparent heat release rate. The first common-rail injection of n-heptane begins at $-57^{\circ}$ ATDC. Near $-40^{\circ}$ ATDC the evaporative cooling and an increase in the heat capacity of the charge resulting from the GDI and first common-rail injections causes the cylinder pressure recorded on the fired cycle to fall slightly below that of the motored trace. At $-37^{\circ}$ ATDC, the second common-rail injection begins and the associated evaporative cooling and heat capacity change causes the cylinder pressure afterwards to further drop below the motored 
trace. Around $-19^{\circ}$ ATDC, low-temperature reactions push the apparent heat release rate above zero. The energy release from these low-temperature reactions reaches a peak near $-13^{\circ}$ ATDC and by $-11^{\circ}$ ATDC enough energy has been released from low-temperature reactions to raise the cylinder pressure above the motored pressure. Because iso-octane is a single stage fuel ${ }^{3}$ (i.e., it generally does not exhibit low temperature heat release) it is expected that the observed lowtemperature heat release is primarily the result of n-heptane decomposition. In fact, Puduppakkam et al. [20] used CFD modeling coupled with a detailed chemical kinetic mechanism (425 species and 3128 reactions) to study RCCI combustion and found that the lowtemperature heat release was primarily due to n-heptane decomposition. After peaking, the energy release decreases to near zero at $-9^{\circ}$ ATDC. The high-temperature heat-release begins near $-6^{\circ}$ ATDC and peaks near $2^{\circ}$ ATDC. The relatively symmetric shape of the hightemperature heat release curve suggests that no mixing-controlled combustion is present, consistent with the long ignition-dwell. However, in comparison to perfectly mixed conditions, the energy release occurs rather slowly; if the charge were perfectly premixed, chemical kinetics calculations show that the charge would ignite nearly uniformly (volumetrically) and the combustion event would be completed within a few crank angle degrees.

\subsection{High Speed Combustion Chemiluminescence Imaging}

Figure 8 shows the two fields of view (FOVs) for combustion chemiluminescence imaging. The illustration on the left shows the FOV with the HSC viewing upward through the flat piston-crown window, while the illustration on the right shows the FOV with the HSC viewing downward through the cylinder head window. Although each pair of bottom-view and

\footnotetext{
${ }^{3}$ Sjöberg et al. [27] have shown that under some conditions (e.g., high boost pressure), iso-octane does show lowtemperature heat release; however, the present study operates at conditions where iso-octane is expected to behave as a single-stage fuel.
} 
top-view images were acquired at the same crank angle, they are from different cycles (only one camera was used), so they are not simultaneous. The time in crank angle degrees after top dead center is shown in the upper-left corner of each image. The solid gray line on the left illustration shows the inner edge of the piston bowl rim, which also bounds the FOV. The FOV through the cylinder-head window is shown by the white dashed line on both images. Notice that approximately $1 / 3$ of the FOV through the cylinder head window images overlaps with the FOV through the piston crown window. The images acquired through the cylinder-head window view downward onto the top of the piston bowl rim, as indicated by the solid gray lines, which show the curvature of the inner surface of the piston bowl (smaller radius) and the cylinder liner (larger radius).

Selected high-temperature combustion chemiluminescence images with FOVs as illustrated in Figure 8 are shown in Figure 9. The presented images are selected from a single cycle that has an AHRR most similar to the ensemble-average AHRR in Figure 7. The appearance of chemiluminescence in the downstream region of the jet between $-5^{\circ}$ and $-7^{\circ}$ ATDC coincides with the transition to second-stage combustion (i.e., high-temperature ignition). Small ignition pockets are initially observed in two locations, inside the edge of the piston bowl rim, and in the squish region (i.e., above the piston bowl-rim). These ignition zones grow for several crank angle degrees while more ignition pockets continue to appear. The separate ignition pockets then merge into larger, more coherent reaction zones. By $-1^{\circ}$ ATDC, the squishwindow image (the right image in each pair) is nearly filled with combustion luminosity ${ }^{4}$. The remainder of the images show that general progression of the reaction zones is back toward the

\footnotetext{
${ }^{4}$ Note that the presented images are integrated in the line-of-sight; therefore, it is not possible to determine the distribution of combustion luminosity into the page (i.e., it is possible that the observed luminosity is occurring at different distances orthogonal to the firedeck).
} 
centrally mounted common-rail injector. Notice that careful inspection of the reaction zones shows that small auto-ignition pockets frequently appear ahead of the main reaction zone. This suggests that the mechanism for reaction-zone progression is sequential auto-ignition; however, more work is required to definitively determine the dominant mechanism of reaction-zone growth.

\subsection{Fuel Distribution}

The chemiluminescence imaging results show that ignition generally occurs in the squish region (i.e., in the FOV of the cylinder-head window); therefore, the fuel tracer PLIF imaging study will focus on the squish region. The fuel-distribution maps are acquired with the ICCD camera viewing downward through the cylinder-head window.

Figure 10 shows the 40-cycle ensemble-averaged PRF maps at several times during the common-rail injection event. The solid gray line on the left side of each PRF map shows the edge of the cylinder-head window FOV (corresponding to the white dotted line in Figure 8). The middle gray line on the PRF maps shows the location of the piston bowl rim and the gray line on the right-hand side of each image shows the location of the cylinder liner. The laser sheet enters from the right side of each image. The fuel enters the FOV of the cylinder-head window images around $-54^{\circ}$ ATDC. Note that at this time, the HSC images (not shown) indicate that liquid fuel is present in the FOV; thus, the vapor-fuel concentration measurements at this crank angle are likely biased by fluorescence and scattering from liquid fuel, and should be considered as upper bounds. Shortly later, at $-50^{\circ}$ ATDC, the first common-rail injection is nearly complete and the fuel-tracer PLIF images show that the vapor fuel has penetrated nearly to the cylinder liner.

By $-45^{\circ}$ ATDC the vapor fuel from the first injection has penetrated to the liner and is beginning to spread along the cylinder wall. Although the fuel injection is over, momentum 
causes the vapor fuel to continue to penetrate, entraining ambient gas (air and iso-octane), and the PRF number in the upstream portion begins to rapidly decrease. The fuel from the first injection continues to mix, and shortly before the fuel vapor from the second common-rail injection enters the FOV (i.e., the images at $-40^{\circ}$ and $-35^{\circ}$ ATDC), the minimum PRF number in the plane of the laser sheet is 55 to 60 .

At $-30^{\circ}$ ATDC, the fuel jet from the second injection enters the FOV and mixes with the fuel from the GDI and first common-rail injection. Because of slower penetration due to the higher ambient densities for the second injection, by the time vapor fuel enters the FOV of the cylinder head window, the fuel injection process is complete. Similar to the first injection, the vapor-fuel jet continues to penetrate after the end of injection; however, now the jet is entraining not only nitrogen (air in the case of combusting conditions) and iso-octane, but also n-heptane from the first injection. Because the n-heptane concentration tends to increase away from the nozzle (i.e., towards the liner), the PRF number of the entrained fuel tends to decrease as the jet moves downstream. By $-25^{\circ}$ ATDC the ensemble-averaged PRF number in head of the jet is approximately 40 (i.e., a 40 - 60 blend of iso-octane and n-heptane). Notice that outside of the region influenced by the second fuel injection, much of the fuel from the first common-rail injection has mixed to create a relatively uniform mixture (in these ensemble-averaged images) in the squish region with a PRF number of ranging from 55 to 60; however, in the upstream region, between the fuel jets, locations exists that are more dominated by the premixed isooctane (on average). The final fuel-tracer PLIF image above the piston bowl rim is at $-21^{\circ}$ ATDC (recall that the optical access window in the cylinder liner becomes blocked by the piston bowl rim at crank angles later than $-21^{\circ}$ ATDC). At this time, a small region in the downstream portion of the jet is at a PRF number near 45 and the PRF number increases on either side of the 
jet as well as upstream towards the injector.

Images from $-21^{\circ}$ ATDC to $-5^{\circ}$ ATDC are acquired inside of the cutout in the piston bowl rim (the imaging layout is shown in Figure 4 (b)). Figure 11 shows the equivalence ratio and PRF (octane number) distributions at several times during the LTHR and near the onset of second-stage combustion. Although the PRF maps shown in Figure 11 are acquired inside of a cutout in the piston bowl-rim and on a plane $3 \mathrm{~mm}$ lower than those shown in Figure 10, the span of the PRF across most of the two images at $-21^{\circ}$ ATDC is similar, ranging from 45 to 60 in Figure 10 and from 50 to 70 in Figure 11. Despite the differences in piston bowl geometry, this similarity is not surprising because the fuel distribution should be dominated by the n-heptane injection rather than by the flow field induced by the piston bowl rim geometry. The n-heptane injection occurs early in the cycle and is not confined in the piston bowl region (as it would be in conventional diesel combustion), so the resulting mixture distributions after compression should be less affected by piston geometry than for fuel injections closer to TDC. As expected from the previous fuel-PLIF imaging sequence, Figure 11 shows that the charge continues to mix in the time between $-21^{\circ}$ and $-5^{\circ}$ ATDC. The region of highest reactivity (lowest PRF number, which for these experiments correlates with the highest equivalence ratio) remains located in the downstream portion of the jet, near the liner. The fuel reactivity decreases with decreasing distance from the center of the combustion chamber (i.e., from right to left in the images in Figure 11). Notice that the bulk in-cylinder swirl moves the highest reactivity regions (lowest PRF number) slightly off the spray axis in the later images.

\subsection{Analysis of Ignition Location and Reaction Zone Growth Direction}

The fuel tracer PLIF measurements (see Figure 11) are combined with ignition delay calculations (chemical kinetics modeling) to explain the observed ignition location and direction 
of reaction zone growth. Chemical kinetics modeling to calculate the ignition delay requires fuel concentration and temperature data, which are simplified according to their radial variation only, as described in the following two paragraphs.

Figure 12 shows the equivalence ratio averaged in the circumferential direction as a function of distance from the center of the combustion chamber at $-10^{\circ}$ ATDC. The $-10^{\circ}$ ATDC image was chosen since it is the last set of images acquired prior to ignition. Both the total equivalence ratio (i.e., due to the contributions of n-heptane and iso-octane) and the iso-octane only (GDI) equivalence ratio are shown. First, as previously discussed, the iso-octane distribution is not perfectly homogenous. This is expected since the fuel is delivered using a direct injection through the side-mounted gasoline direct injector. However, the spread in the iso-octane distribution is reasonably small, ranging from $\phi=0.29$ near the liner to $\phi=0.22$ at $30 \mathrm{~mm}$ from the bore center. Recall that the fuel-tracer PLIF measurements are focused on ignition, which generally occurs in the FOV of the cylinder-head window; therefore, the fuel distribution close to the cylinder centerline is not measured. However, a clear trend of decreasing equivalence ratio with decreasing distance from the center of the combustion chamber is evident. With this trend in mind, the fuel distribution in the center of the combustion chamber can be estimated by extrapolating the measured equivalence ratio toward the center of the combustion chamber. To estimate the iso-octane equivalence ratio in the near-nozzle region, we assume that the iso-octane distribution remains constant at the value measured at $30 \mathrm{~mm}$ from the bore center $(\phi=0.22)$. We further assume that the n-heptane distribution continues the linear decrease observed in the measurements.

Similar trends can be extracted from the PRF and temperature distributions. Figure 13 shows the corresponding measured and extrapolated PRF and temperature curves (averaged in 
the circumferential direction) at $-10^{\circ}$ ATDC. Note that the extrapolated PRF values are calculated using the extrapolated equivalence ratio values shown in Figure 12. The temperature field is calculated from the fuel tracer fluorescence images; however, the absolute value of the temperature should be considered an estimate based on the assumption of adiabatic mixing. The extrapolated temperature is assumed to be linear until the PRF value reached 100 at $18 \mathrm{~mm}$ from the bore center.

Figure 14 shows the constant volume ignition delay, calculated using the SENKIN code [21] with the reduced PRF mechanism developed by Ra et al. [22]. The reduced PRF mechanism consists of 45 species and 145 reactions describing the combined oxidation of iso-octane and nheptane. The mechanism has been shown to yield accurate results under RCCI combustion conditions [23]. The ignition delay calculations were initialized at the measured pressure and with the range of temperature and fuel concentrations in Figure 12 and Figure 13. At the operating conditions investigated in the present study, ignition occurs in broad zones that occupy a large fraction of the combustion chamber volume. Hence, the pressure rise associated with initial ignition heat release is significant, and can affect the progression of ignition chemistry. To account for this pressure coupling, the ignition delay calculations were treated as constant volume, rather than as constant pressure. Furthermore, combustion takes place near top-dead center where the chamber volume change is small during the ignition process.

Figure 14 is helpful to interpret the effect of equivalence ratio, PRF, and temperature stratification; however, the results should be interpreted with caution since they represent the ignition delay of an isolated mixture (i.e., with no interaction from the surrounding regions). Even without considering the effects of transport, the ignition delay of the less reactive regions (i.e., higher PRF number or lower equivalence ratio) will decrease as they become hotter when 
they are compressed by the expansion of other regions that have already ignited. However, even with uncertainties in the measured equivalence ratio, PRF, and temperature as well as with the ignition delay kinetics, the predictions of Figure 14 are at least qualitatively in agreement with the chemiluminescence images. That is, the ignition delay is shortest near the cylinder liner (long distance from bore center) and there is a gradient in ignition delay (fuel reactivity) from the liner to the cylinder centerline.

Figure 14 shows that the PRF number and equivalence ratio are the prime determinants of the location of first ignition, which is in the squish region for the hardware and operating conditions studied here. For other operating conditions at higher in-cylinder density (e.g., higher load), or for a common-rail injector with a narrower included angle, the location of the mixtures that yield first ignition may be farther from the cylinder liner and/or in the piston bowl. Whatever the location of ignition, the progression of combustion after ignition should follow the same characteristic dependency observed here, proceeding down the reactivity gradient.

Also notice in Figure 14 that the PRF and equivalence-ratio stratification appear to outweigh the temperature stratification. That is, the temperature gradient would suggest that ignition should occur near the center of the chamber (in the hottest region), while PRF and equivalence ratio gradients suggest that ignition should occur in the outer region of the chamber. The relative roles of equivalence ratio stratification, PRF stratification, and temperature stratification are discussed in the next section.

\subsection{Relative Roles of Equivalence Ratio and Fuel Blend Stratification}

Dec et al. [3] have shown that the rate of heat release can be controlled by tailoring the fuel distribution using a single fuel (i.e., equivalence-ratio stratification). In the RCCI strategy, stratification in PRF (octane number), equivalence ratio, and temperature (due to evaporative 
cooling and changes in the specific heat ratio) are present. Thus, it is of interest to understand the relative roles of equivalence ratio, $\mathrm{PRF}$, and temperature stratification. The constant-volume ignition-delay calculations discussed in the previous section are repeated using a $2^{3}$ design of experiments (DOE) to isolate these effects. Table 5 shows the design matrix.

Figure 15 shows predicted ignition delays as function of distance from the bore center for each case, and Figure 16 shows the difference in predicted ignition delay between the least reactive and most reactive regions. Case 1 is the same as that presented in Figure 14, and the difference between the least reactive and most reactive regions is $22.5 \mathrm{~ms}$. Case 2 shows the ignition delay with the temperature stratification removed from the Case 1 simulation. As discussed previously, the temperature stratification competes with the equivalence ratio and PRF stratification (i.e., regions with low PRF numbers and high equivalence ratios have low temperatures due to evaporative cooling); therefore, removing the temperature stratification increases the spread between the least reactive and most reactive regions to $26 \mathrm{~ms}$. Although the temperature stratification does have a small effect on the ignition delay, Figure 16 shows that the ignition delay is dominated by the equivalence ratio and PRF stratification (notice that the case with only temperature stratification (Case 7) has a nearly constant ignition delay, as discussed in the next section). Therefore, the remaining discussion will compare case pairs with and without temperature stratification. Cases 3 and 4 show the ignition delay without equivalence ratio stratification. Removing the equivalence ratio stratification reduces the spread in ignition delay to approximately $12 \mathrm{~ms}$. Cases 5 and 6 show the ignition delay without PRF stratification. Removing the PRF stratification reduces the spread in ignition delay to approximately $8 \mathrm{~ms}$.

Figure 16 shows that, although both equivalence ratio and PRF stratification are both important, PRF stratification has the largest effect on ignition delay. Furthermore, the level of 
equivalence ratio stratification is limited by the equivalence ratios of approximately 0.2 to 0.5 to maintain high efficiency, clean combustion. On the low side $(\phi=0.2)$, reactions are too slow and combustion efficiency is poor. On the high side $(\phi=0.5)$ flame temperatures are high enough to form enough NOx to require exhaust aftertreatment. The addition of PRF stratification to equivalence ratio stratification thereby allows greater control over the rate of heat release for a given level of equivalence ratio stratification. For a given load point, PRF stratification can broaden the combustion duration to allow the combustion phasing (CA50) to be advanced more than with equivalence ratio-stratification alone, thereby improving thermal efficiency at a given pressure-rise rate.

Although the ignition-delay calculations employed here cannot directly predict the combustion duration, the relative change in ignition delay between the most reactive and least reactive regions in the chamber (see Figure 16) is expected to correlate with the change in combustion duration through gradients into the auto-ignition characteristics (i.e., the ignition delay) of the charge. Relying on Zel'dovich [24], Chen et al. [25] relate the speed of a propagating subsonic spontaneous ignition front, $S_{i g}$, to the spatial gradient in ignition delay, $\nabla \tau$, as

$$
s_{i g}=\frac{1}{|\nabla \tau|} .
$$

For example, it is expected that removing the PRF stratification and using equivalence ratio stratification only (i.e., case 5) would shorten the combustion duration by a factor of $\sim 3$ (i.e., reducing the CA10 to 90 time $13^{\circ}$ to $4^{\circ}$ ), increasing the peak rate of heat release by a similar factor, and possibly resulting in unacceptably high pressure-rise rate. Alternatively, there may be some portions of the operating map where it is desirable to shorten the combustion duration (e.g., low-load, high-speed operation). Thus, reducing the difference in ignition delay 
between the most reactive and least reactive regions in the combustion chamber (i.e., moving towards case 8 by increasing the mixing between the two fuels) may improve the engine efficiency.

It is interesting that the temperature stratification has only a minor effect on ignition delay. Notice that, although the temperature gradient is nearly linear, the effect of temperature stratification is largest in the center of the combustion chamber and nearly negligible towards the cylinder liner (see Figure 15). Recall that the PRF gradient is approximately the inverse of the temperature gradient; thus, it appears that the temperature stratification is most important when the fuel is primarily iso-octane (i.e., a single-stage ignition fuel). To illustrate this, Figure 17 shows the change in ignition delay over the temperature gradient shown in Figure 15 at a constant equivalence ratio of 0.37 and several different PRF numbers. A positive ignition delay difference means that the ignition delay at the liner $(\mathrm{T}=826 \mathrm{~K})$ is shorter than the ignition delay at the center of the combustion chamber $(\mathrm{T}=845 \mathrm{~K})$. For primary reference fuel blends from 0 to 75, the NTC behavior results in a nearly constant ignition-delay. The ignition delay is shortest in the cooler regions at PRF blends of 50 and less. As the PRF is increased past 50, the ignition delay is shortest in the higher temperature regions. The effect of temperature stratification is largest when the fuel is neat iso-octane. The NTC behavior of PRF 0 (neat n-heptane), PRF 50, and PRF 100 is shown in Figure 18. The combination of Figure 17 and Figure 18 clearly show that the reason for the negligible temperature stratification effect at the current operating condition (i.e., temperatures ranging from 825 to $845 \mathrm{~K}$ as in Figure 13) is the NTC behavior of the primary reference fuel. For ignition in more heterogeneous distributions and/or with strong mixing, this NTC behavior would likely be much less prominent than in these kinetics-only calculations. Given that the measured fuel distributions have relatively weak gradients, and 
ignition is long after the period of strong turbulent mixing created by the fuel injection event, little additional mixing should be occurring late in the compression stroke when the mixtures ignite. Hence, the predicted NTC behavior should be representative of the ignition kinetics in the real engine.

\section{Conclusions}

The combustion process in a dual-fuel, RCCI engine was investigated using a combination of optical diagnostics and chemical kinetics modeling. A high-speed camera imaged the injection events and recorded high-temperature combustion chemiluminescence. The high-speed chemiluminescence imaging showed that ignition occurs in the outer region of the combustion chamber (near the cylinder liner) in small, isolated ignition pockets. These ignition zones grew for several crank angle degrees while more ignition pockets continued to appear. The separate ignition pockets then merged into larger, more coherent reaction zones and moved steadily back towards the center of the combustion chamber. A non-reacting fuel tracer PLIF diagnostic quantified the fuel distribution prior to ignition. The results from the fuel PLIF diagnostic showed that the combustion event followed gradients in the n-heptane concentration. Chemical kinetics modeling based on the fuel tracer fluorescence imaging isolated the roles of temperature, equivalence ratio, and PRF number stratification. PRF number stratification was found to be the dominant factor controlling the ignition location and growth rate of the reaction zone. Equivalence ratio had a smaller, but still significant, influence. At the operating conditions of the present study, temperature stratification had a negligible influence due to the NTC behavior of the PRF mixture. 


\section{References}

[1] S.W. Park and R.D. Reitz, "Numerical Study on the Low Emission Window of Homogeneous Charge Compression Ignition Diesel Combustion," Comb. Sci. Tech., 179 (11) (2007) 2279-2307.

[2] P.M. Najt and D.E. Foster, "Compression-Ignited Homogeneous Charge Combustion," SAE Trans., 92 (1) (1983) 964-979 (SAE Technical Paper 830264).

[3] J.E. Dec, Y. Yang, and N. Dronniou, "Boosted HCCI - Controlling Pressure-Rise Rates for Performance Improvements using Partial Fuel Stratification with Conventional Gasoline," SAE Int. J. Engines, 4 (1) (2011) 1169-1189 (SAE Technical Paper 2011-01-0897).

[4] J.E. Dec, "Advanced Compression-ignition Engines-Understanding the In-cylinder Processes," Proc. Combust. Inst., 32 (2) (2009) 2727-2742.

[5] M. Sjoberg and J.E. Dec, "Smoothing HCCI Heat-Release Rates Using Partial Fuel Stratification with Two-Stage Ignition Fuels," SAE Trans., 115 (3) (2006) 318-334 (SAE Technical Paper 200601-0629).

[6] J.E. Dec, W. Hwang, and M. Sjöberg, "An Investigation of Thermal Stratification in HCCI Engines Using Chemiluminescence Imaging," SAE Trans., 115 (3) (2006) 759-776 (SAE Technical Paper 2006-01-1518).

[7] M. Sjoberg, J.E. Dec, and N.P. Cernansky, "Potential of Thermal Stratification and Combustion Retard for Reducing Pressure-Rise Rates in HCCI Engines, Based on Multi-Zone Modeling and Experiments," SAE Trans., 114 (3) (2005) 236-251 (SAE Technical Paper 2005-01-0113).

[8] S.L. Kokjohn, R.M. Hanson, D.A. Splitter, and R.D. Reitz, "Experiments and Modeling of Dual-fuel HCCI and PCCI Combustion using In-cylinder Fuel Blending," SAE Int. J. Engines, 2 (2) (2010) 2439 (SAE Technical Paper 2009-01-2647).

[9] R.M. Hanson, S.L. Kokjohn, D.A. Splitter, and R.D. Reitz, "An Experimental Investigation of Fuel Reactivity Controlled PCCI Combustion in a Heavy-Duty Engine," SAE Int. J. Engines, 3 (1) (2010) 700-716 (SAE Technical Paper 2010-01-0864).

[10] S.L. Kokjohn, R.M. Hanson, D.A. Splitter, J. Kaddatz, and R.D. Reitz, "Fuel Reactivity Controlled Compression Ignition (RCCI) Combustion in Light- and Heavy-Duty Engines," SAE Int. J. Engines, 4 (1) (2011) 360-374 (SAE Technical Paper 2011-01-0357).

[11] S.L. Kokjohn, R.M. Hanson, D.A. Splitter, and R.D. Reitz, "Fuel Reactivity Controlled Compression Ignition Combustion: A Pathway to High Efficiency Clean Combustion," Int. J. Engine Res., 12 (3) (2011) 209-226.

[12] D.A. Splitter, R.M. Hanson, S.L. Kokjohn, K. Rein, S. Sanders, and R.D. Reitz, "An Optical Investigation of Ignition Processes in Fuel Reactivity Controlled PCCI Combustion," SAE Int. J. Engines, 3 (1) (2010) 142-162 (SAE Technical Paper 2010-01-0345).

[13] C. Genzale, R.D. Reitz, and M.P. B Musculus, "Effects of Piston Bowl Geometry on Mixture Development and Late-Injection Low-Temperature Combustion in a Heavy-Duty Diesel Engine," SAE Int. J. Engines, 1 (1) (2008) 913-937 (SAE Technical Paper 2008-01-1330).

[14] J.E. Dec, "A Conceptual Model of DI Diesel Combustion Based on Laser-Sheet Imaging," SAE Transactions, 106 (3) (1997) 1319-1348 (SAE Technical Paper 970873).

[15] J.B. Heywood, Internal Combustion Engine Fundamentals.: McGraw-Hill, 1988.

[16] A. Hultqvist, M. Christensen, B. Johansson, A. Franke, M. Richter, and M. Aldén, "A Study of the Homogeneous Charge Compression Ignition Combustion Process by Chemiluminescence Imaging," SAE Trans., 108 (3) (1999) 2114-2127 (SAE Technical Paper 1999-01-3680).

[17] W. Hwang, J. Dec, and M. Sjoberg, "Spectroscopic and Chemical-kinetic Analysis of the Phases of 
HCCI Autoignition and Combustion for Single- and Two-stage Ignition Fuels," Combust. Flame, 154 (3) (2008) 387-409.

[18] C. Schulz and V. Sick, "Tracer-LIF Diagnostics: Quantitative Measurement of Fuel Concentration, Temperature and fuel/air Ratio in Practical Combustion Systems," Prog. Energy Combust. Sci., 31 (1) (2005) 75-121.

[19] M.P. B. Musculus, T. Lachaux, L.M. Pickett, and C.A. Idicheria, "End-of-Injection Over-Mixing and Unburned Hydrocarbon Emissions in Low-Temperature-Combustion Diesel Engines," SAE Trans., 116 (3) (2007) 515-541 (SAE Technical Paper 2007-01-0907).

[20] K.V. Puduppakkam, L. Liang, C.V. Naik, E. Meeks, S.L. Kokjohn, and R.D. Reitz, "Use of Detailed Kinetics and Advanced Chemistry-Solution Techniques in CFD to Investigate Dual-Fuel Engine Concepts," SAE Int. J. Engines, 4 (1) (2011) 1127-1149 (SAE Technical Paper 2011-01-0895).

[21] A.E. Lutz, R.J. Kee, and J.A. Miller, "SENKIN: A FORTRAN Program for Predicting Homogeneous Gas Phase Chemical Kinetics with Sensitivity Analysis," SAND 89-8009 (1988).

[22] Y. Ra and R.D. Reitz, "A Combustion Model for IC Engine Combustion Simulations with Multicomponent Fuels," Combust. Flame, 158 (1) (2011) 69-90.

[23] S.L. Kokjohn, "Reactivity Controlled Compression Igntion (RCCI) Combustion," PhD Thesis in Mechanical Engineering, University of Wisconsin - Madison (2012).

[24] Y.B. Zeldovich, "Regime Classification of an Exothermic Reaction with Non-uniform Initial Conditions," Combust. Flame, 39 (2) (1980) 211-214.

[25] J.H. Chen, E.R. Hawkes, R. Sankaran, S.D. Mason, and H.G. Im, "Direct Numerical Simulation of Ignition Front Propagation in a Constant Volume with Temperature Inhomogeneities: I. Fundamental Analysis and Diagnostics," Combust. Flame, 145 (1-2) (2006) 128-144.

[26] S.L. Kokjohn, R.D.,Splitter, D.A. Reitz, and M.P.B. Musculus, "Investigation of Fuel Reactivity Stratification for Controlling PCI Heat-Release Rates Using High-Speed Chemiluminescence Imaging and Fuel Tracer Fluorescence," SAE Int. J. Engines, 5 (2) (2012) 248-269 (SAE Technical Paper 2012-01-0375).

[27] M. Sjöberg and J.E. Dec, "Effects of Engine Speed, Fueling Rate, and Combustion Phasing on the Thermal Stratification Required to Limit HCCI Knocking Intensity," SAE Trans., 114 (3) (2005) 1472-1486 (SAE Technical Paper 2005-01-2125).

\section{Acknowledgements}

The analysis and simulation work was supported by the US Department of Energy (DOE) contract \# DE-EE0000202 and from the Engine Research Center's Direct-injection Engine Research Consortium (DERC) member companies. The optical engine experiments were performed at the Combustion Research Facility, Sandia National Laboratories, Livermore, CA. Support for this research was provided by the U.S. Department of Energy, Office of Vehicle Technologies. Sandia is a multi-program laboratory operated by Sandia Corporation, a Lockheed

Martin Company for the United States Department of Energy's National Nuclear Security 
Administration under contract DE-AC04-94AL85000. The authors gratefully acknowledge the contributions of Chris Carlen and Dave Cicone for their assistance in maintaining the lasers and research engine used in this study. 


\section{Table Captions}

Table 1. Sandia heavy-duty optical engine specifications.

Table 2. Gasoline direct injector (GDI) specifications.

Table 3. XPI common-rail (CR) fuel injector specs.

Table 4. Engine operating condition for the baseline RCCI optical engine experiments.

Table 5. Design matrix used for constant-volume ignition delay calculations to isolate the influence of equivalence ratio, $P R F$, and temperature stratification. The radial PRF and temperature stratification is shown in Figure 13, and the radial equivalence-ratio stratification is shown in Figure 12. 


\section{Figure Captions}

Figure 1. Layout of combustion chamber at TDC.

Figure 2. Schematic of the optically accessible research engine showing the camera setup for (a) the highspeed chemiluminescence imaging and (b) the toluene fuel-tracer PLIF imaging.

Figure 3. Drawing of GDI injector pattern.

Figure 4. Laser sheet setup for the fuel-tracer PLIF imaging study. (a): Laser-sheet location for the earlycycle images acquired above the piston bowl-rim. (b) Laser-sheet location for the near TDC images acquired inside the cutout in the piston bowl-rim. The cylinder-head window field of view is indicated by the red dashed line. The top row of (a) and (b) shows a top view of the imaging setup and the bottom row shows a side view.

Figure 5. Relative toluene fluorescence used to generate calibration curve. The fueling was held constant at 39 mg/inj. Calibration data from Kokjohn et al. [26].

Figure 6. Image processing procedure for toluene fuel-tracer PLIF imaging.

Figure 7. Measured cylinder pressure (fired and motored), common-rail (n-heptane) ROI, and apparent heatrelease rate. The GDI injection of iso-octane has an SOI timing of $-\mathbf{2 4 0}{ }^{\circ}$ ATDC (not shown).

Figure 8. Camera FOV for both imaging locations. Note that the cylinder-head window FOV is enlarged by a scale factor of 1.7 (also in Figure 9) to more clearly show the ignition process in the squish region.

Figure 9. High-speed camera image sequence of RCCI combustion. Crank angle is indicated in the upper-left corner of each image pair. The images on the left side of each image pair were acquired with the HSC viewing upward through the flat piston-crown window, while the images on the right side of each pair were acquired looking downward through the cylinder-head window. (See Figure 8 for an illustration of the image layout). Note that two sets of images were not acquired simultaneously.

Figure 10. Sequence of ensemble-averaged PRF maps at several times during the common-rail injection event. The time in crank angle degrees after TDC is shown in the upper left hand corner of each image. The PRF maps were generated from vapor-fuel concentration measurements with the camera viewing downward through the cylinder-head window. The relative error in the PRF number images is approximately $7 \%$ of the measured value with a filter size of $0.25 \mathrm{~mm}$ and $3.4 \%$ of the measured value with a filter size of $1 \mathrm{~mm}$.

Figure 11. Sequence of ensemble-averaged PRF map at several times prior to ignition. The time in crank angle degrees after TDC is shown in the upper left hand corner of each image. The laser sheet is located 13 mm below the firedeck. The relative error in the equivalence ratio and PRF number images is approximately $7 \%$ of the measured value with a filter size of $0.25 \mathrm{~mm}$ and $3.4 \%$ of the measured value with a filter size of 1 mm.

Figure 12. Radial variation of the circumferentially averaged equivalence ratio at $-10^{\circ}$ ATDC from the fuel tracer PLIF measurements. The blue lines show the total equivalence ratio (i.e., due to the contributions of n-heptane and iso-octane) and the red lines show the iso-octane only (GDI) equivalence ratio. The solid lines are measured values and the dashed lines are extrapolated. At any given distance from the bore center, the equivalence ratio is relatively uniform in the circumferential direction, with a variation at one standard deviation of approximately $\pm 0.06 \phi$. Similarly, the standard deviation in the circumferential direction for the GDI equivalence ratio distribution is $\pm 0.02 \phi$.

Figure 13. Radial variation of circumferentially averaged PRF (octane number) and temperature at $-10^{\circ}$ ATDC. The solid lines are measured values and the dashed lines are extrapolated. The standard deviation in the circumferential direction for the PRF number and temperature are nearly constant at \pm 5 PRF and $\pm 5 K$ from the liner to the inner edge of the field of view.

Figure 14. Radial variation of predicted ignition delay at $-10^{\circ}$ ATDC from constant-volume chemical kinetics simulations. 
Figure 15. Radial variation of the predicted ignition delay from constant-volume chemical kinetics simulations showing the effects of various combinations of equivalence ratio $(\varphi)$, PRF, and temperature stratification.

Figure 16. Difference in predicted ignition delay between least reactive and most reactive regions for the cases shown in Table 5 and plotted in Figure 15.

Figure 17. Difference in predicted ignition delay from the cylinder liner $(T=826 \mathrm{~K})$ to the center of the combustion chamber $(T=845 \mathrm{~K})$. A positive number indicates a shorter ignition delay at the liner than at the center of the combustion chamber.

Figure 18. Predicted ignition delay over a range of temperatures at $\phi=0.37$ and an initial pressure of 26.5 bar. The shaded region shows the temperature range derived from the fuel tracer PLIF images at $-10^{\circ}$ ATDC. 


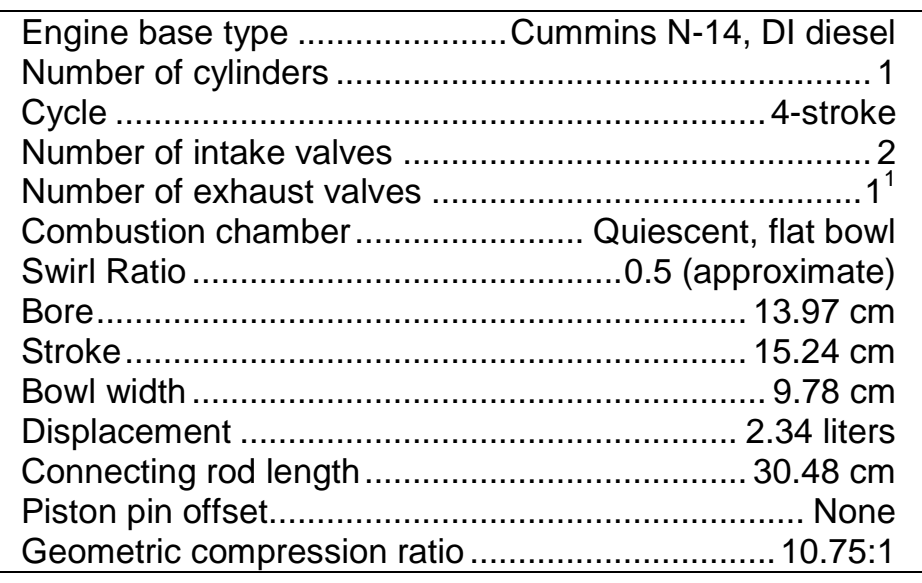

${ }^{1}$ One of the two exhaust valves of the production cylinder head has been replaced by a window and periscope 
Table 2

Injector type ................................................. Bosch GDI Fuel .................................high-purity $(99 \%+)$ iso-octane

Number of holes....................................... 7, asymmetric

Supply pressure ..............................................100 bar

Nominal orifice diameter ............................. 150 micron 
Table 3

Injector type...................common-rail, solenoid actuated Fuel .....................................HPLC-grade n-heptane

Cup (tip) type. mini-sac

Number of holes ................................ 8 , equally spaced

Included angle ................................................152

Rail pressure ...........................................600 bar

Orifice treatment................................ hydroground $8 \%$

Nominal orifice diameter ........................... 140 micron 


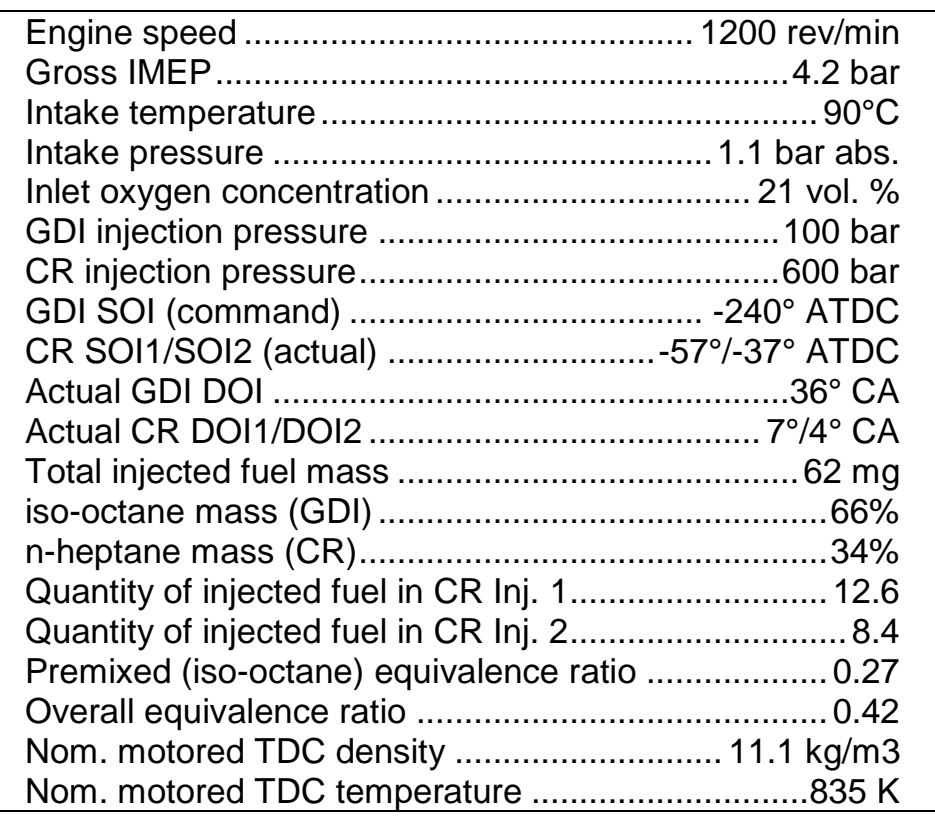


Table 5

\begin{tabular}{cccc}
\hline Case & PRF & $\phi$ & Temperature $[\mathrm{K}]$ \\
\hline 1 & Stratified & Stratified & Stratified \\
2 & Stratified & Stratified & 832 \\
3 & Stratified & 0.37 & Stratified \\
4 & Stratified & 0.37 & 832 \\
5 & 74.3 & Stratified & Stratified \\
6 & 74.3 & Stratified & 832 \\
7 & 74.3 & 0.37 & Stratified \\
8 & 74.3 & 0.37 & 832 \\
\hline
\end{tabular}




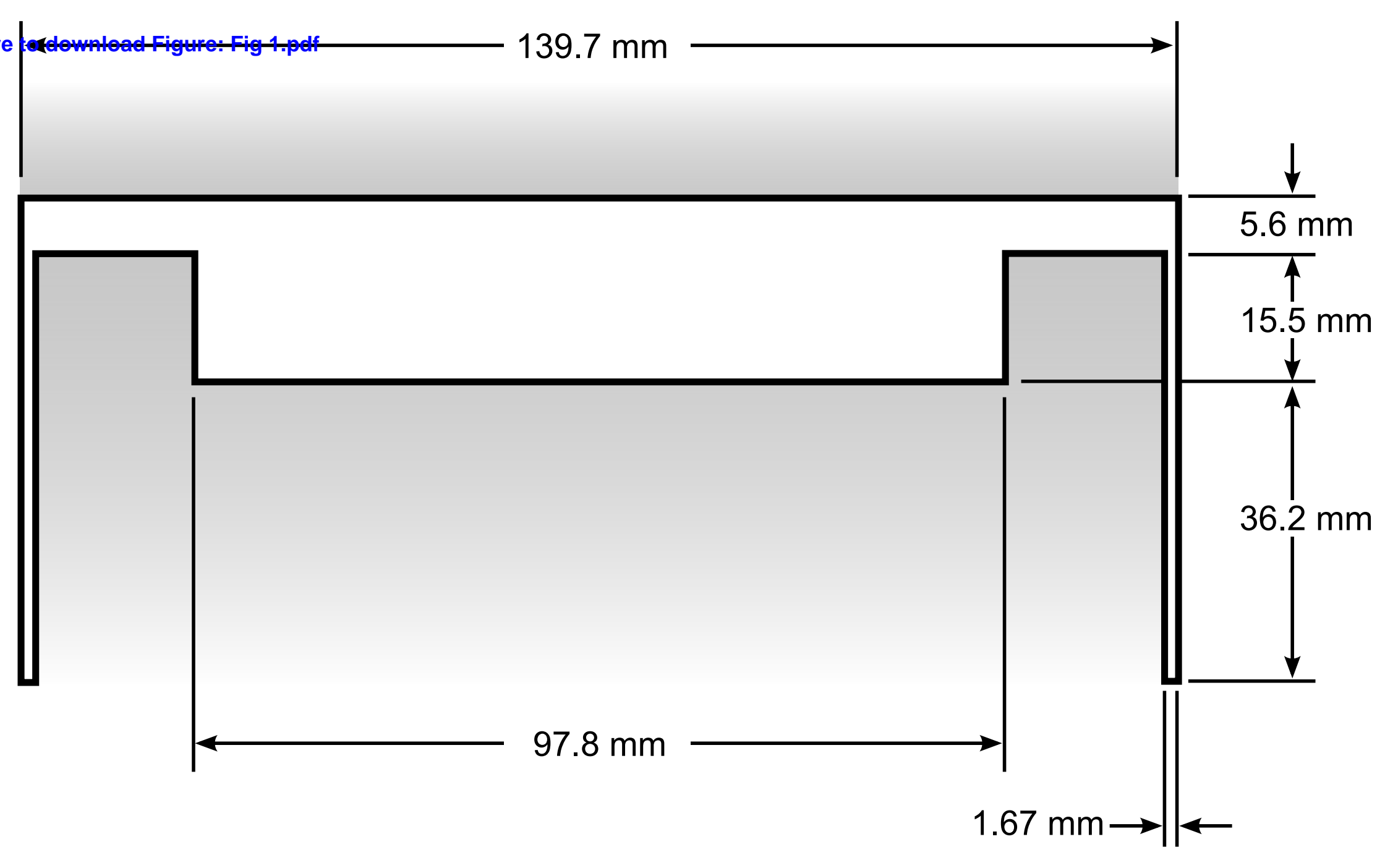



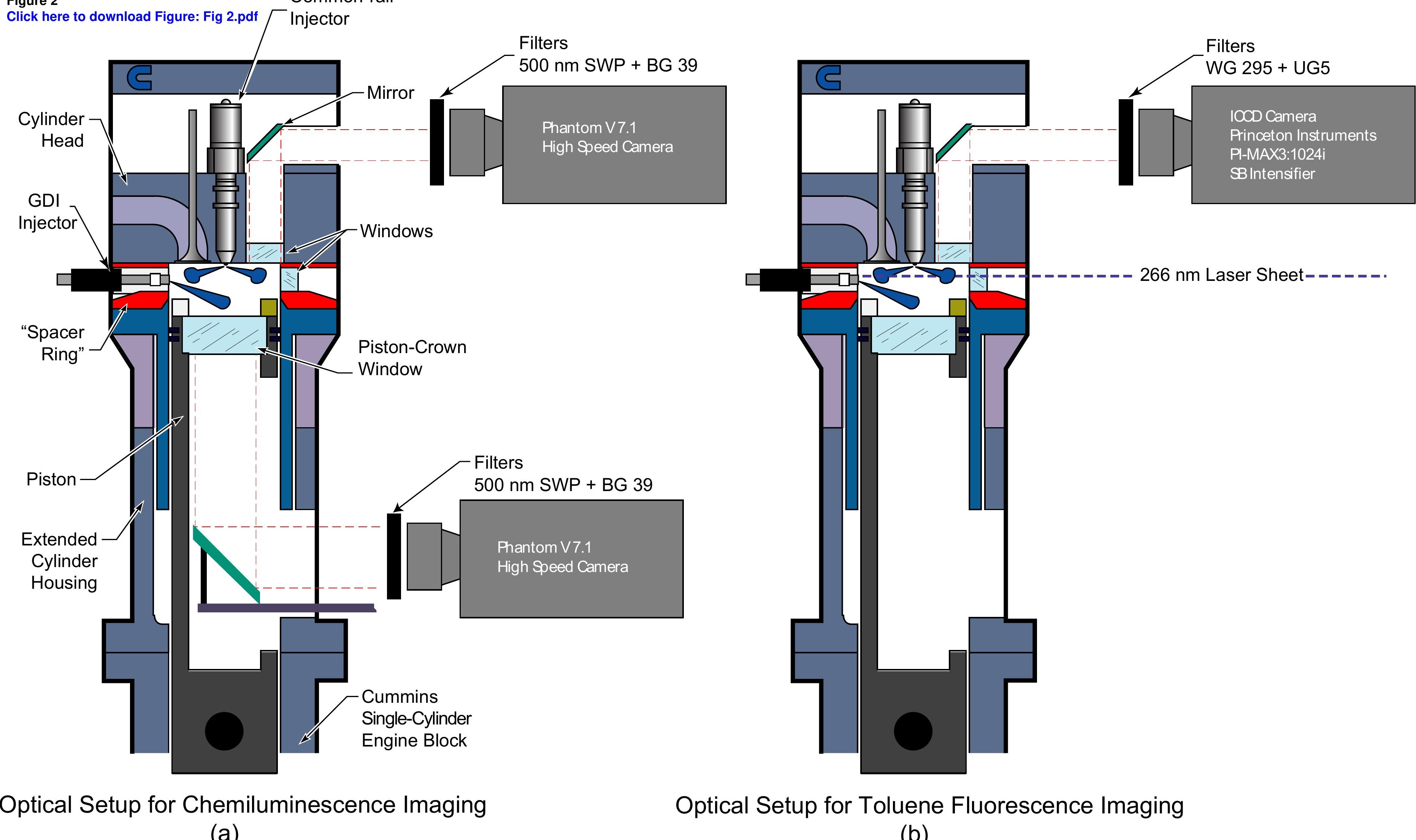

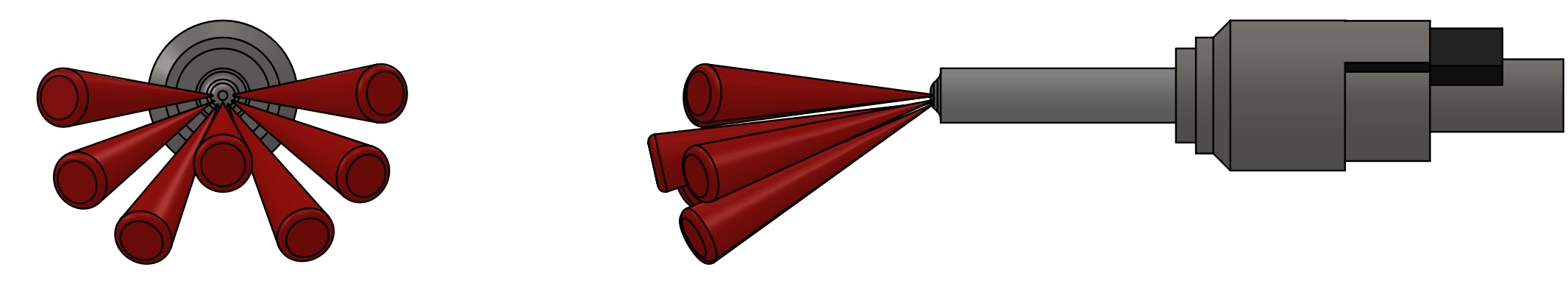
Click here to download Figure: Fig 4.pdf

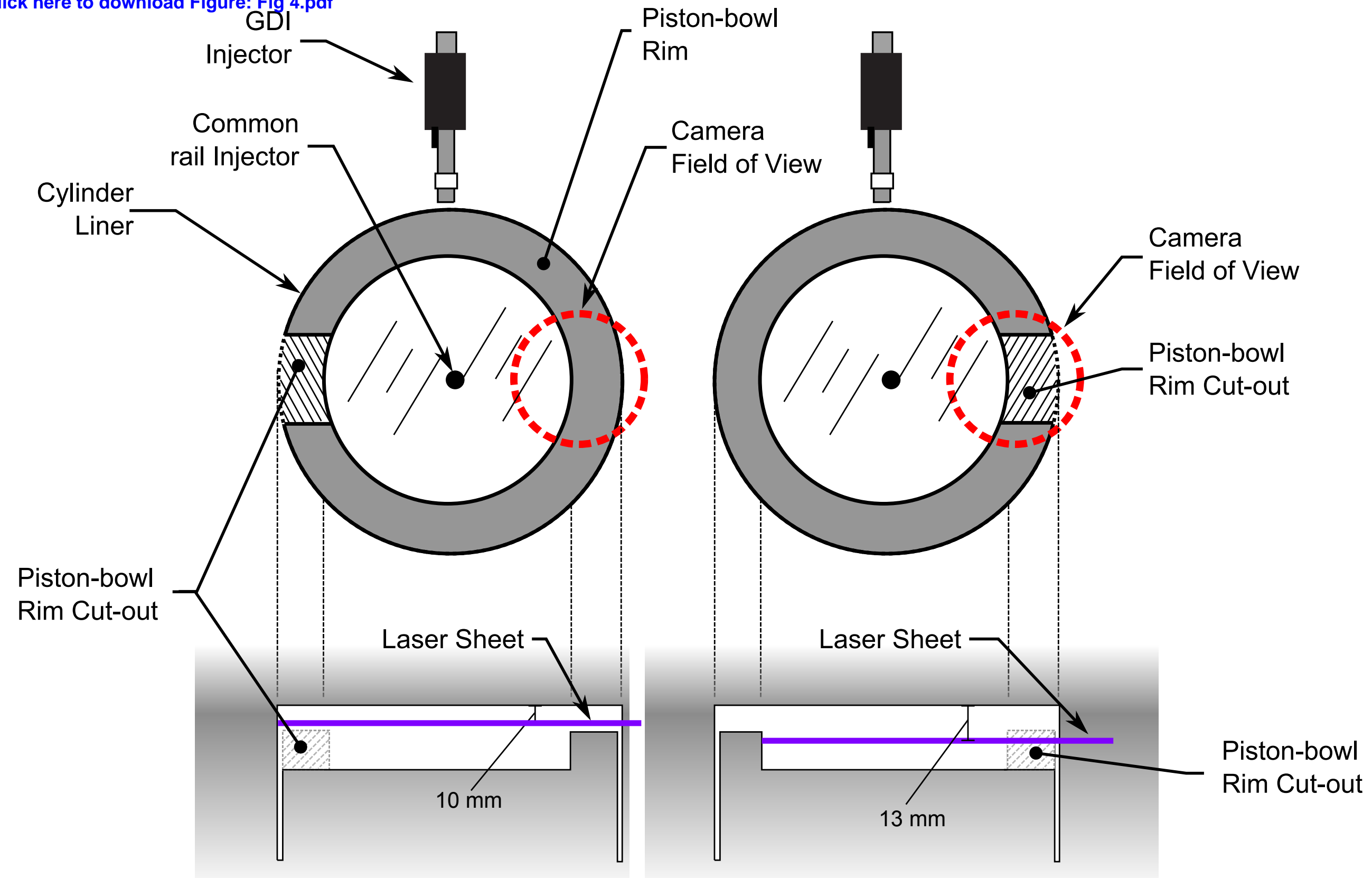

(a) 


\section{Figure 5}

Click here tollownload Figure: Fig 5.pdf

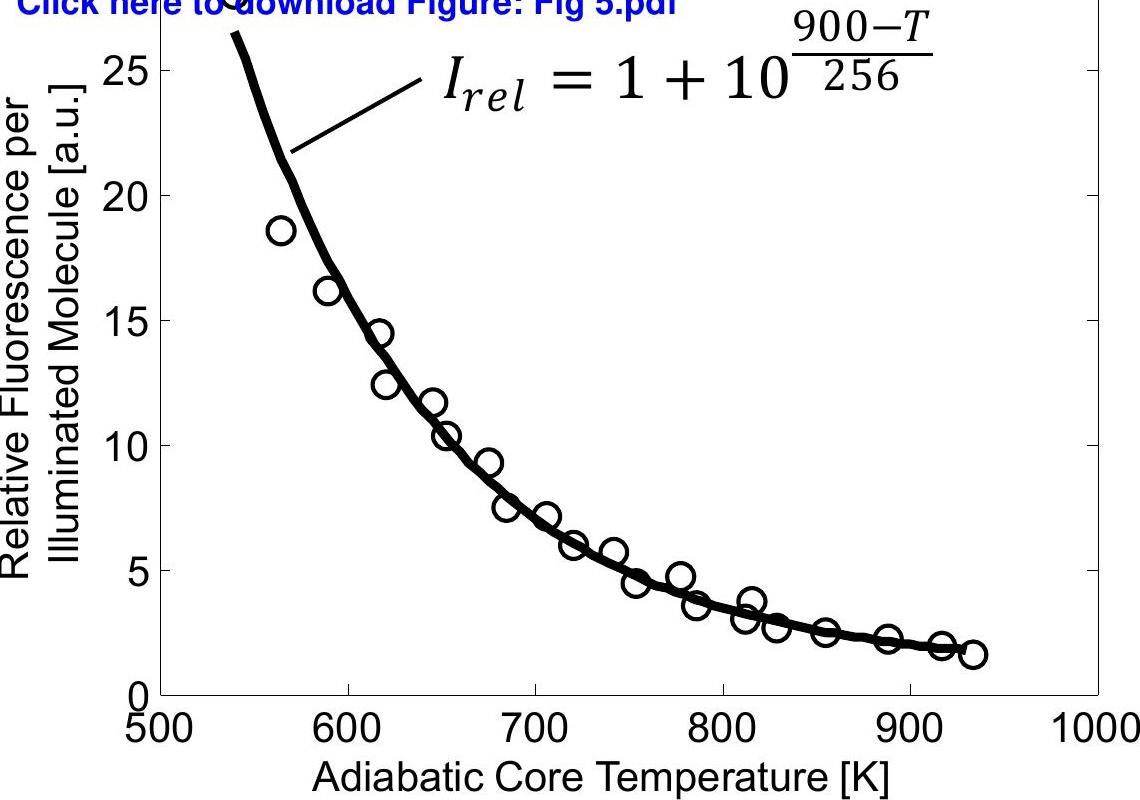


Figure 6

ClickAtesaluqfownload Figure: Fig 6.pdf

uniform

temperature

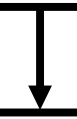

Calculate the fuel distribution using Eq. 2

Calculate the sol temp. distribution using adiabatic mixing

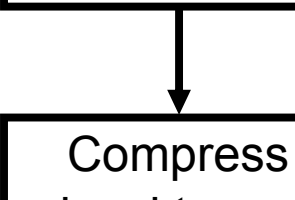
local temp. distribution to imaging crank angle

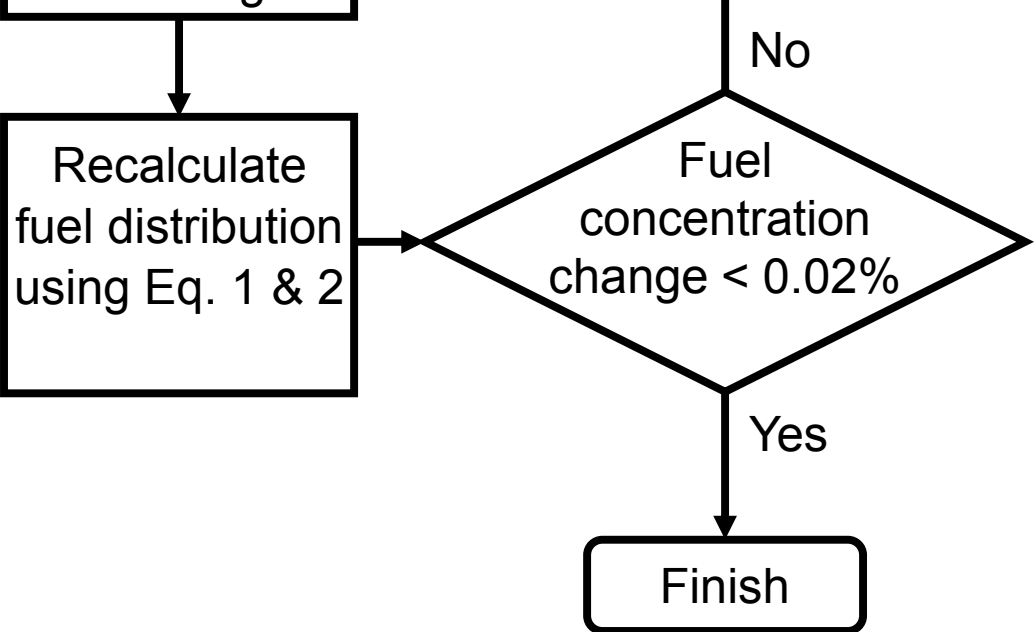


Click here to download Figure: Fig 7.pdf

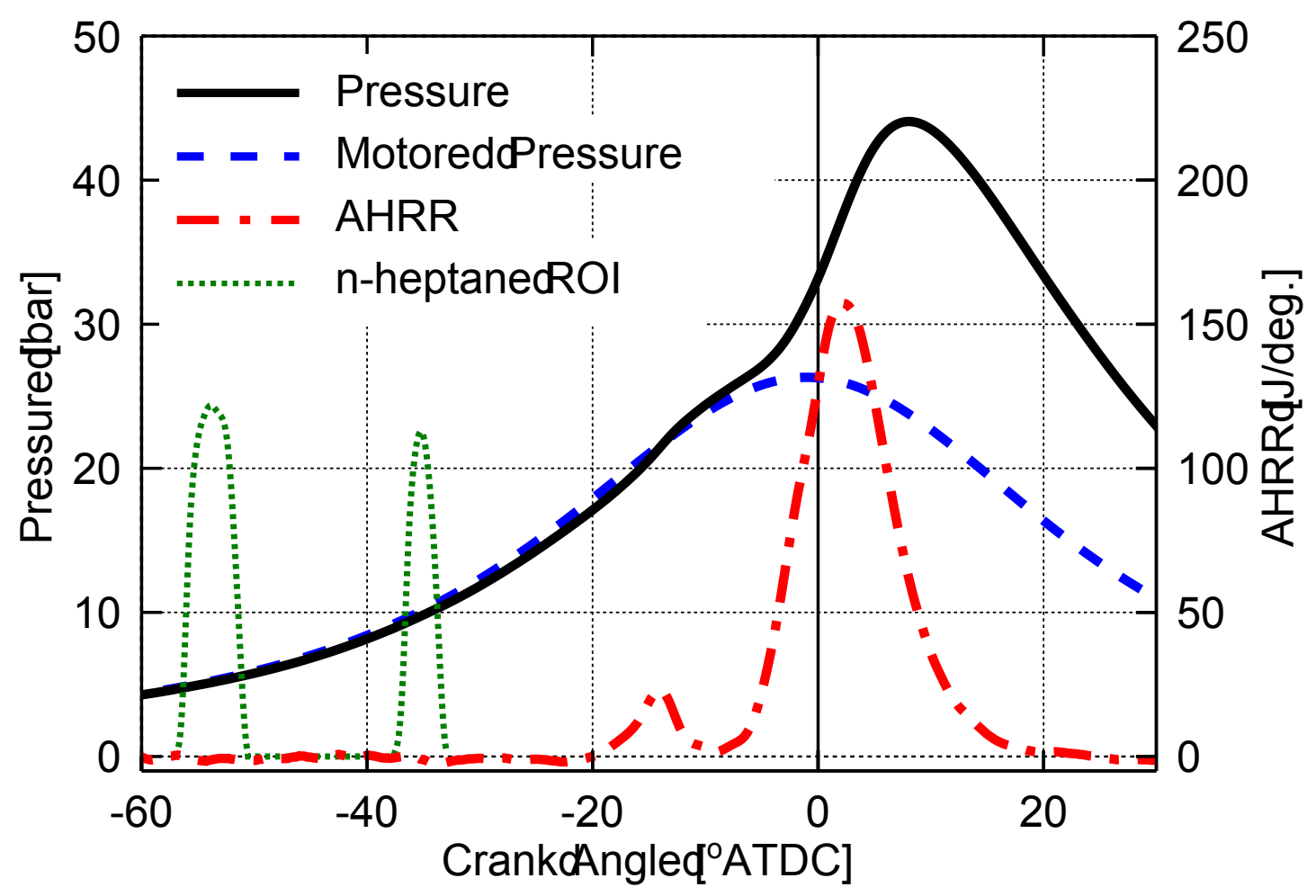




\section{Piston Crown Cylinder Head}

\section{Window Images Window Images}

Commin-rail

Injector

Piston Bowl Rim

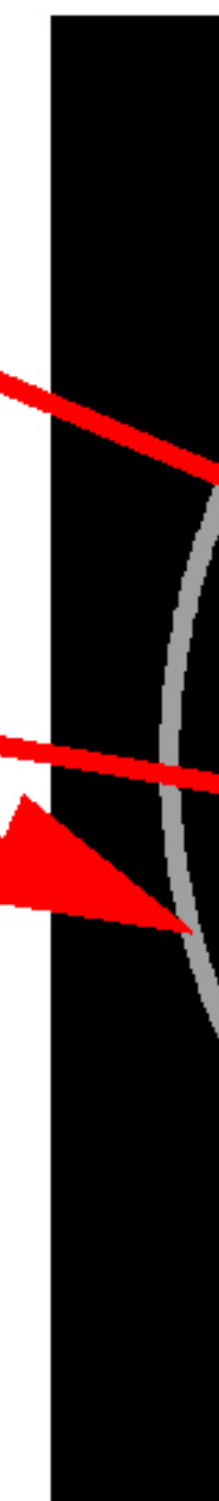

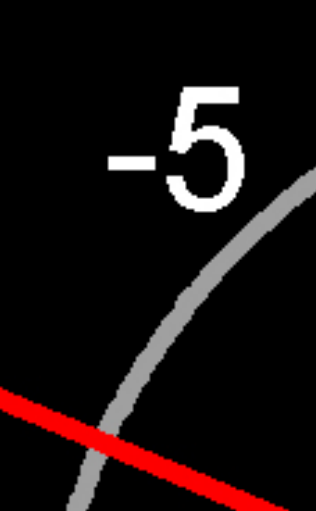
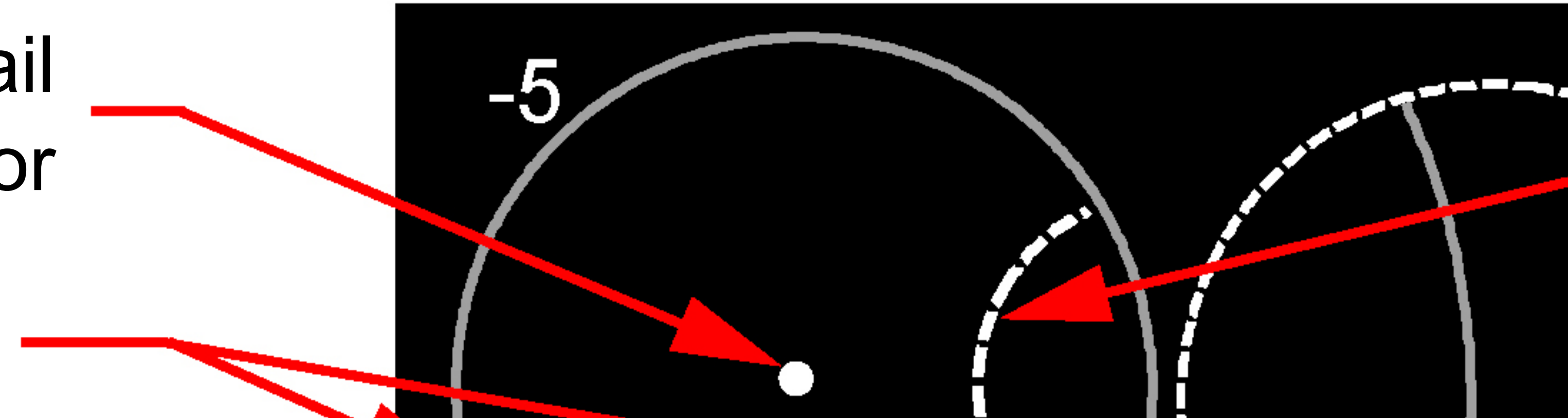

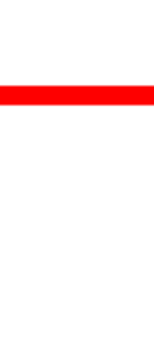


PRF Number [-]

$\begin{array}{lllllllll}20 & 30 & 40 & 50 & 60 & 70 & 80 & 90 & 100\end{array}$
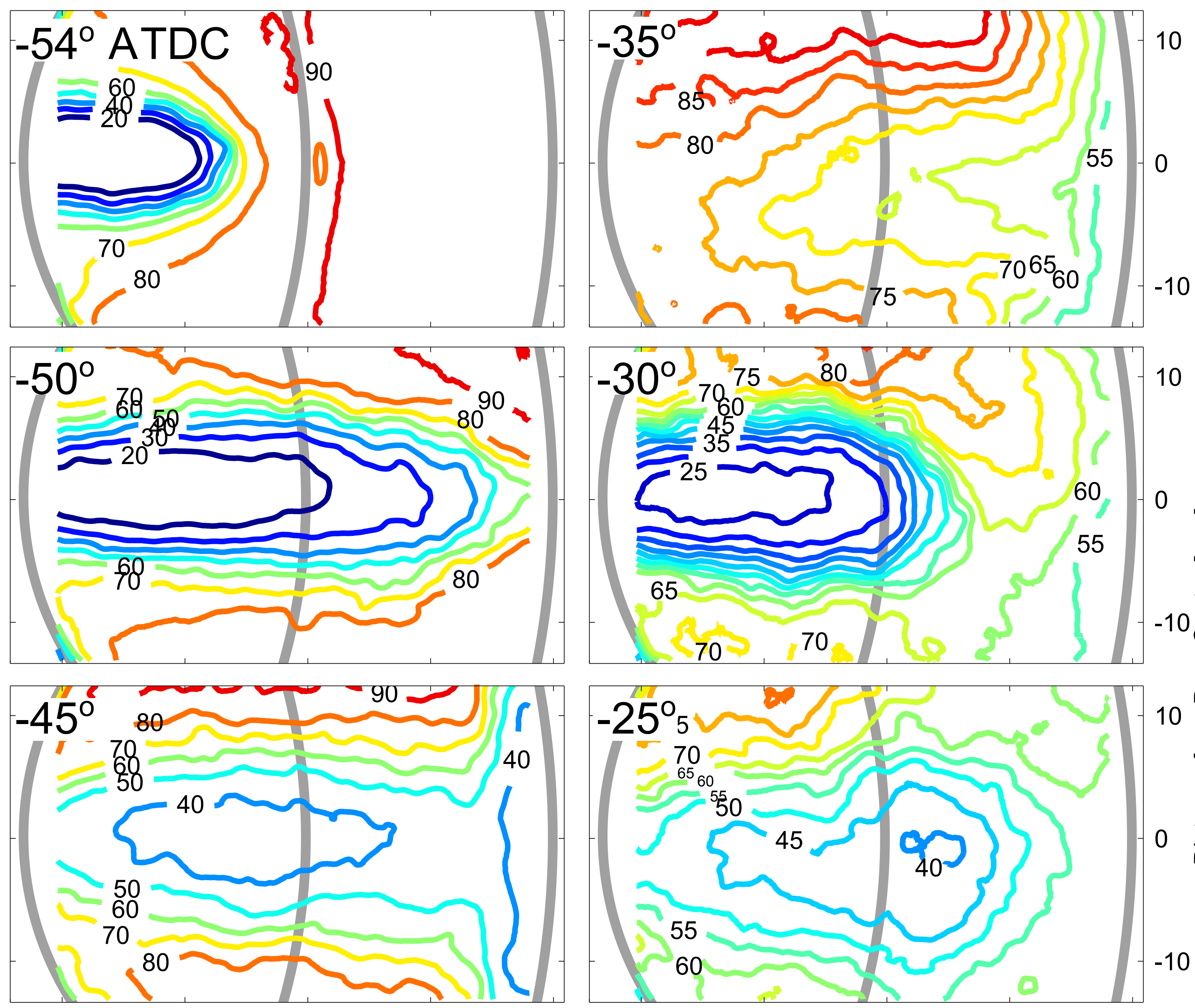

10
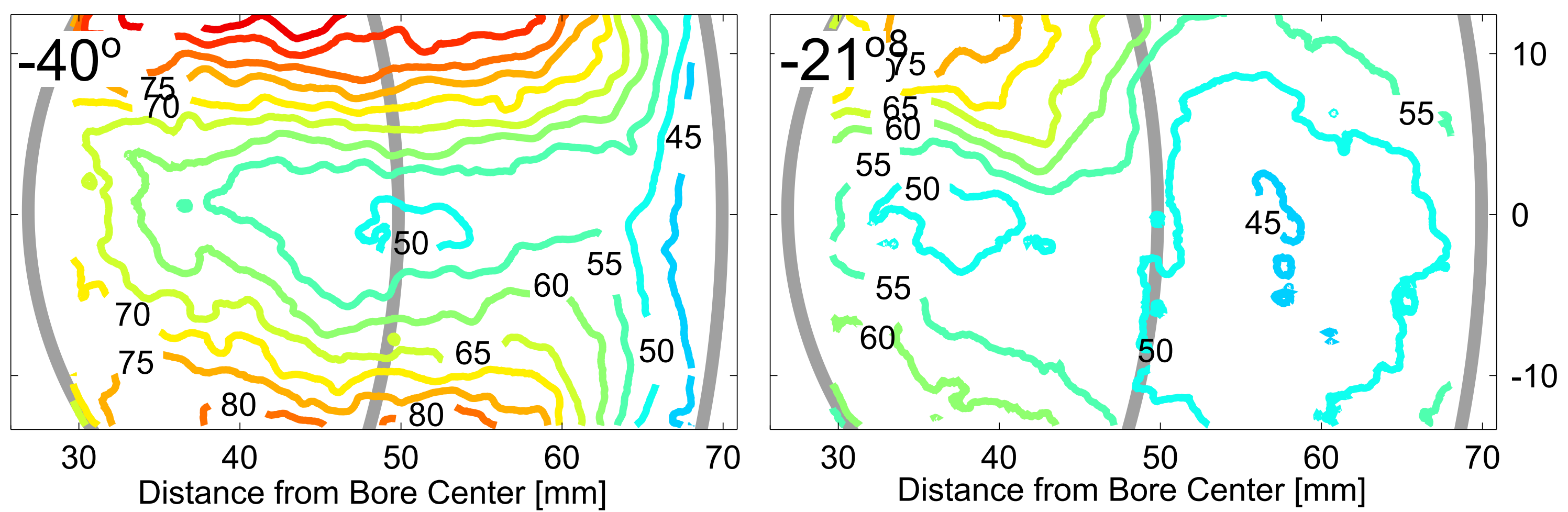
$\begin{array}{lllllll}0.1 & 0.2 & 0.3 & 0.4 & 0.5 & 0.6 & 0.7\end{array}$
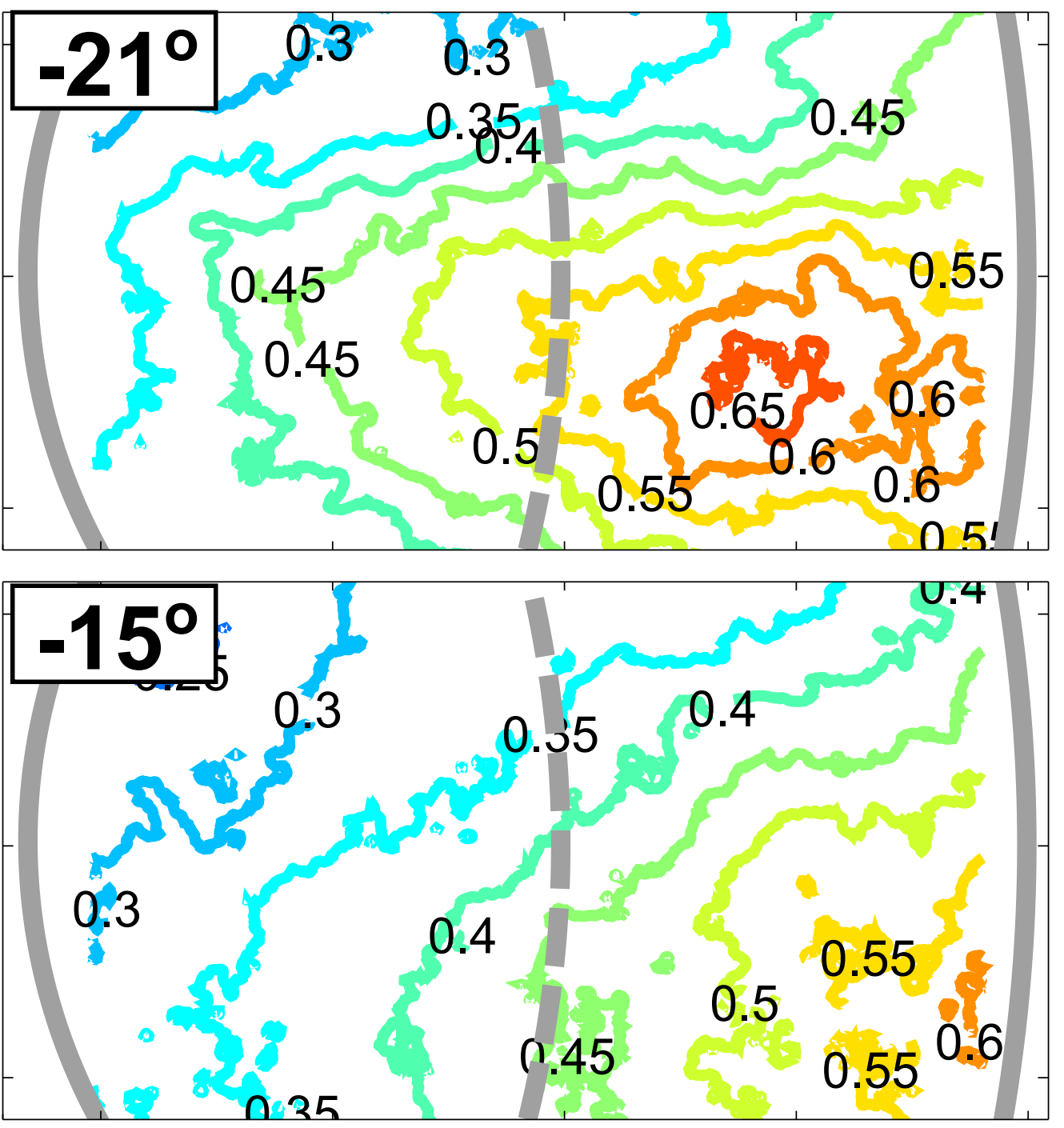

$-10^{\circ} 0.3$

0.35

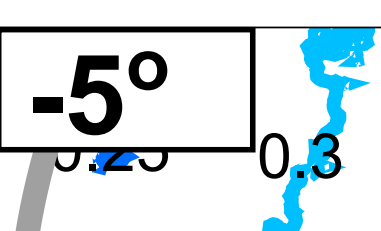
0.4

0.35

$0.15 \quad 0.5$

0.55

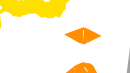

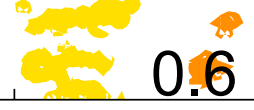

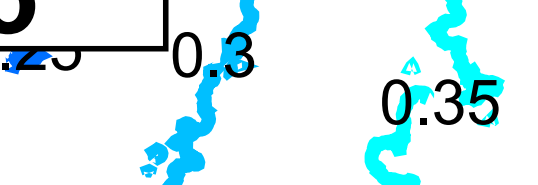

$-0.3$

0.4

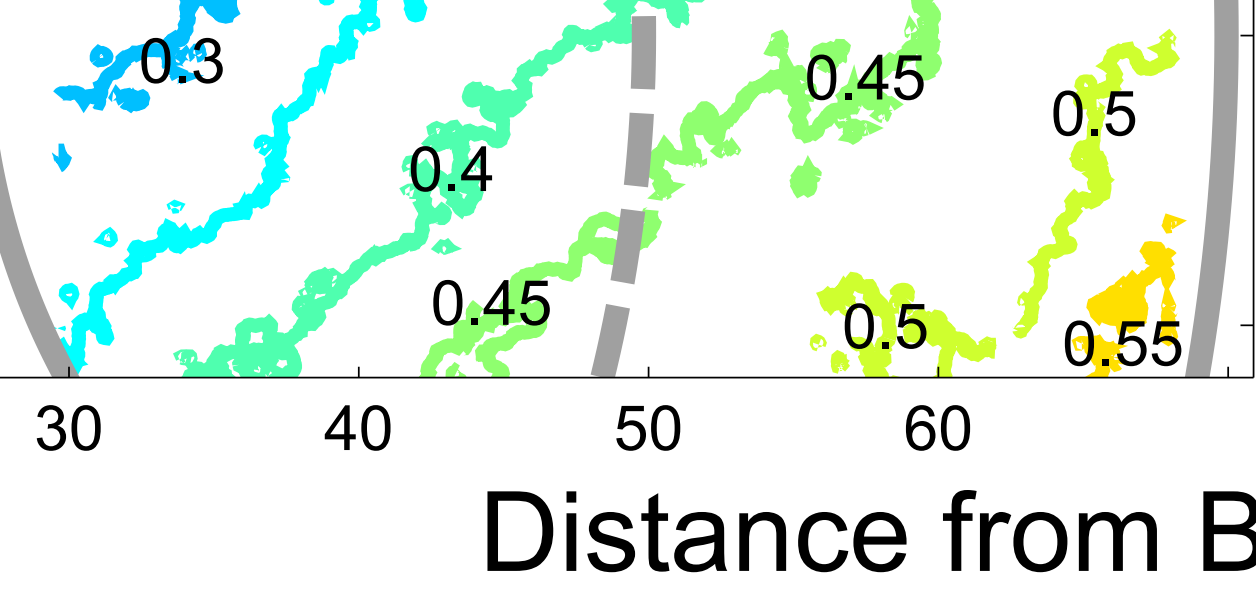

30

0.5<smiles>[TeH]</smiles>

(2)

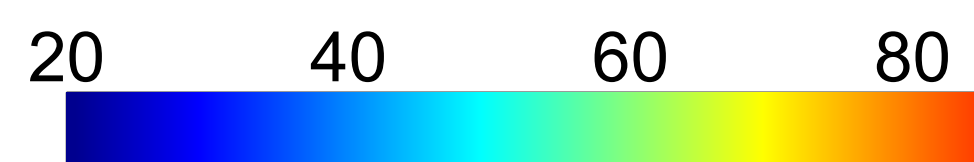

100
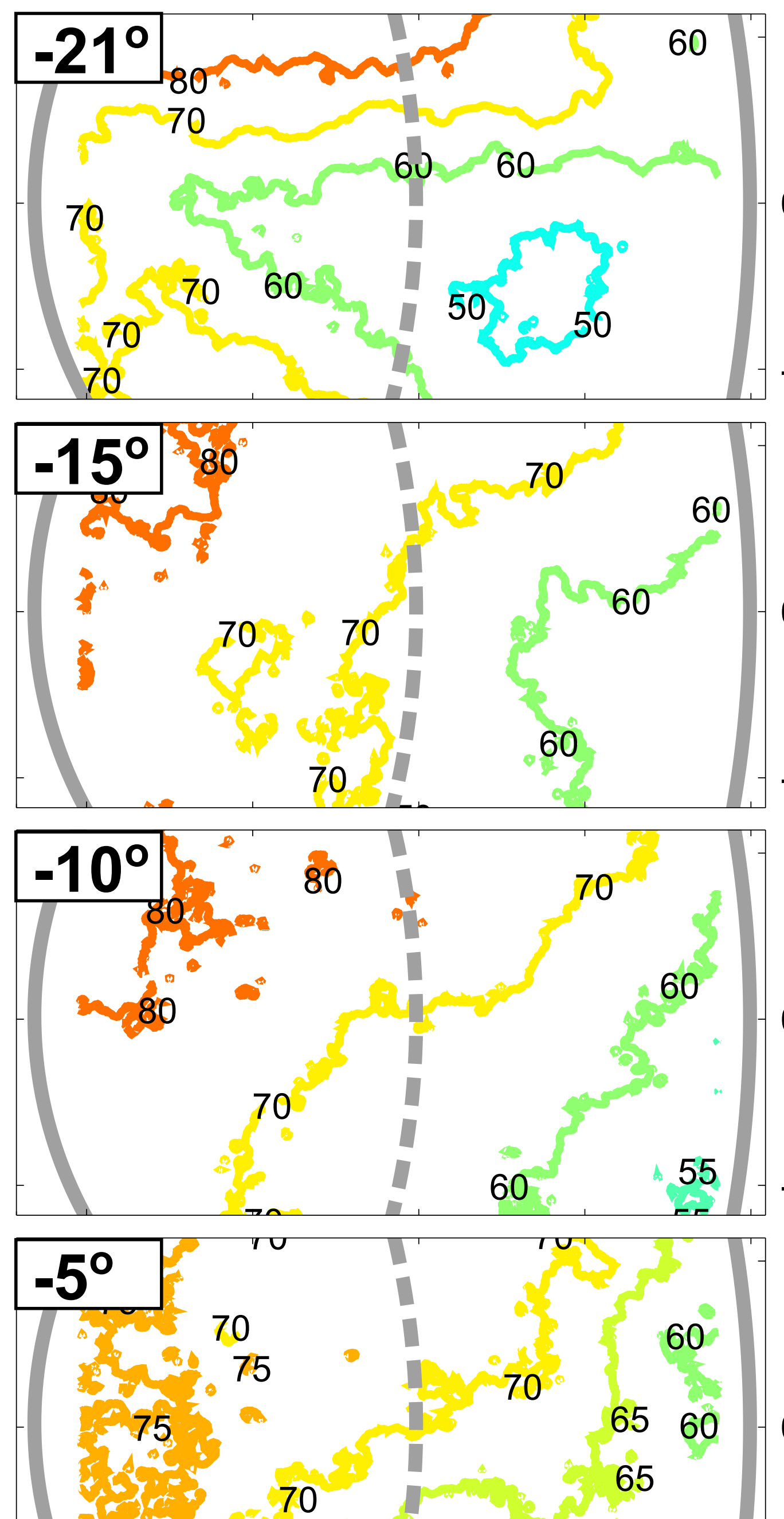

70 65

60

70

$65 \quad 60-0$ 65
$-10$

10

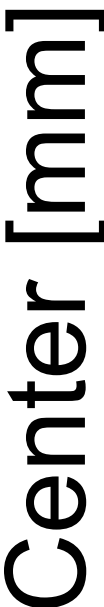

$-10$ 10

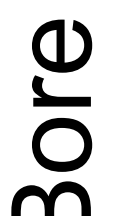

? 7 - 65

s. 60 an $60,-10$ $30 \quad 40$ 50 60 70 0 Bore Center [mm] 


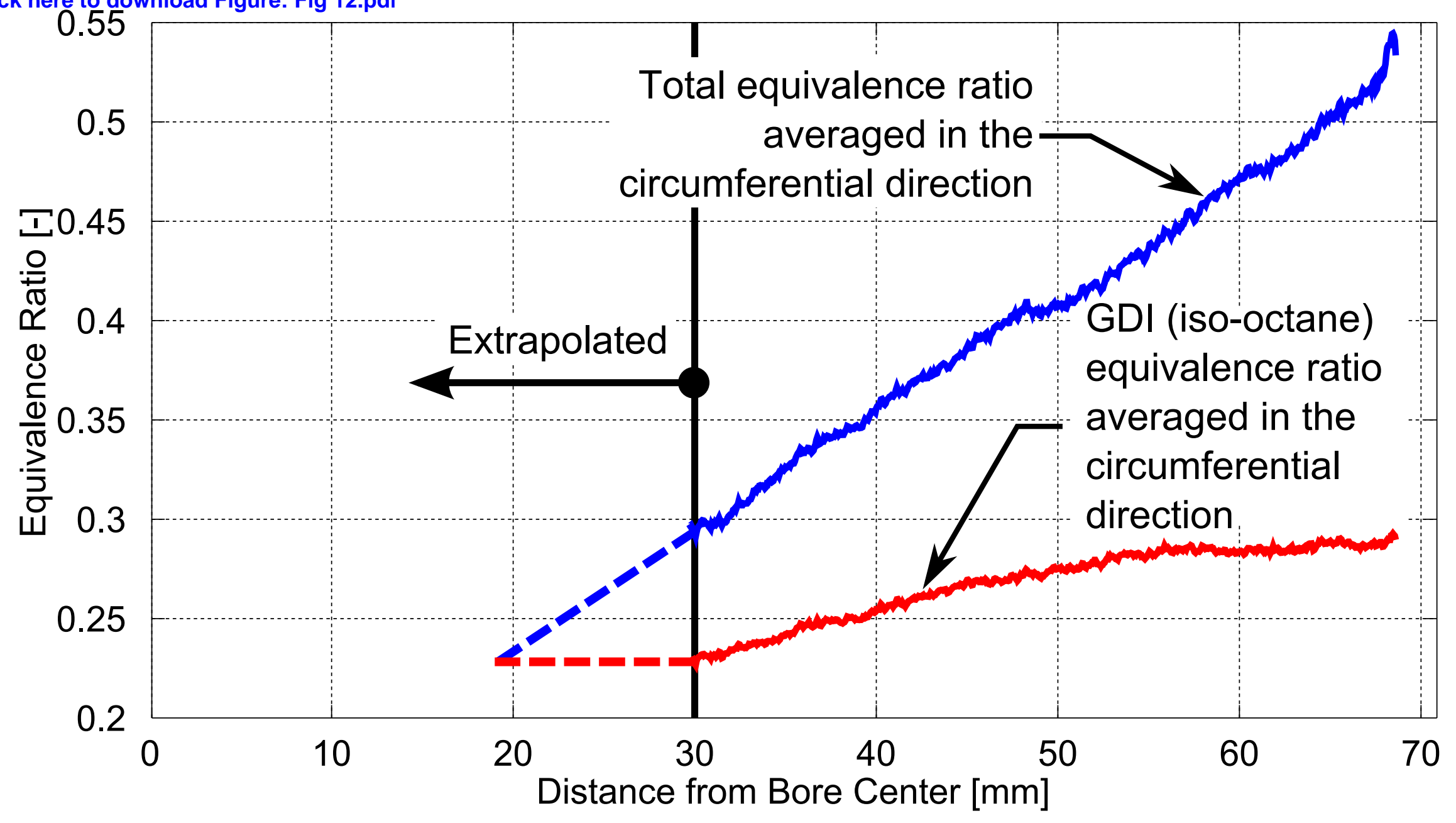




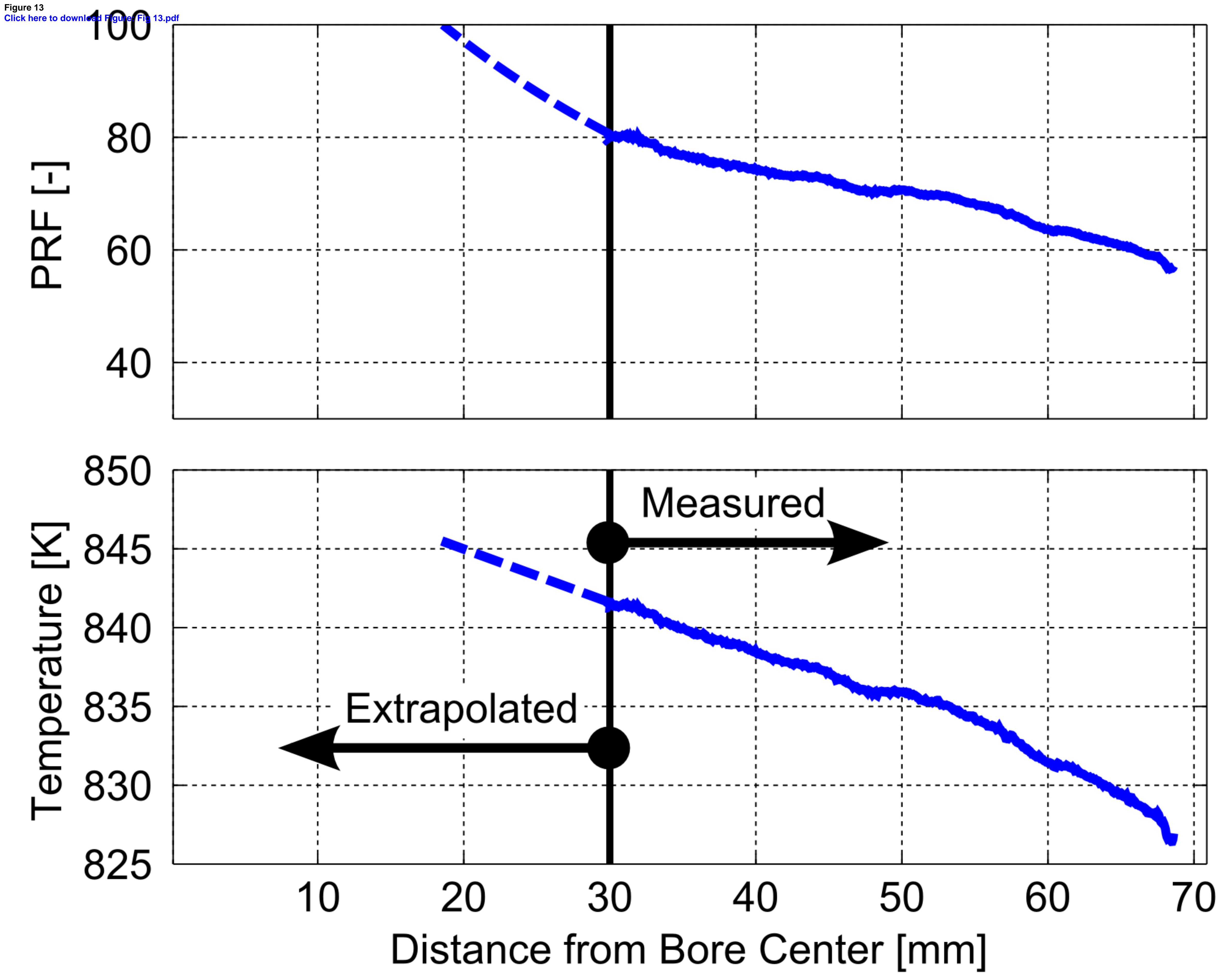


Figure 14

Click hoge to download Figure: Fig 14.pdf

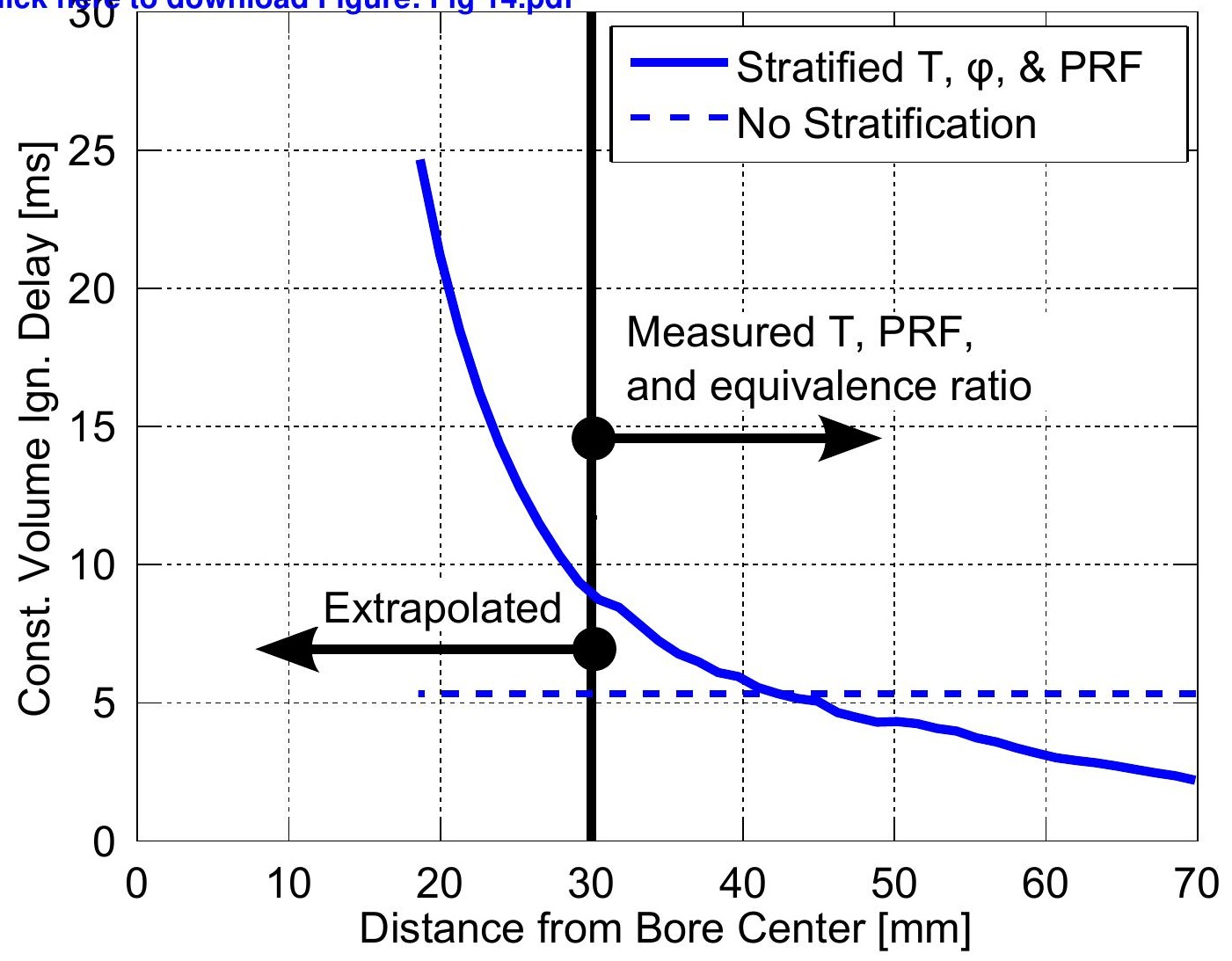


Figure 15

Click hefe to download Figure: Fig 15.pdf

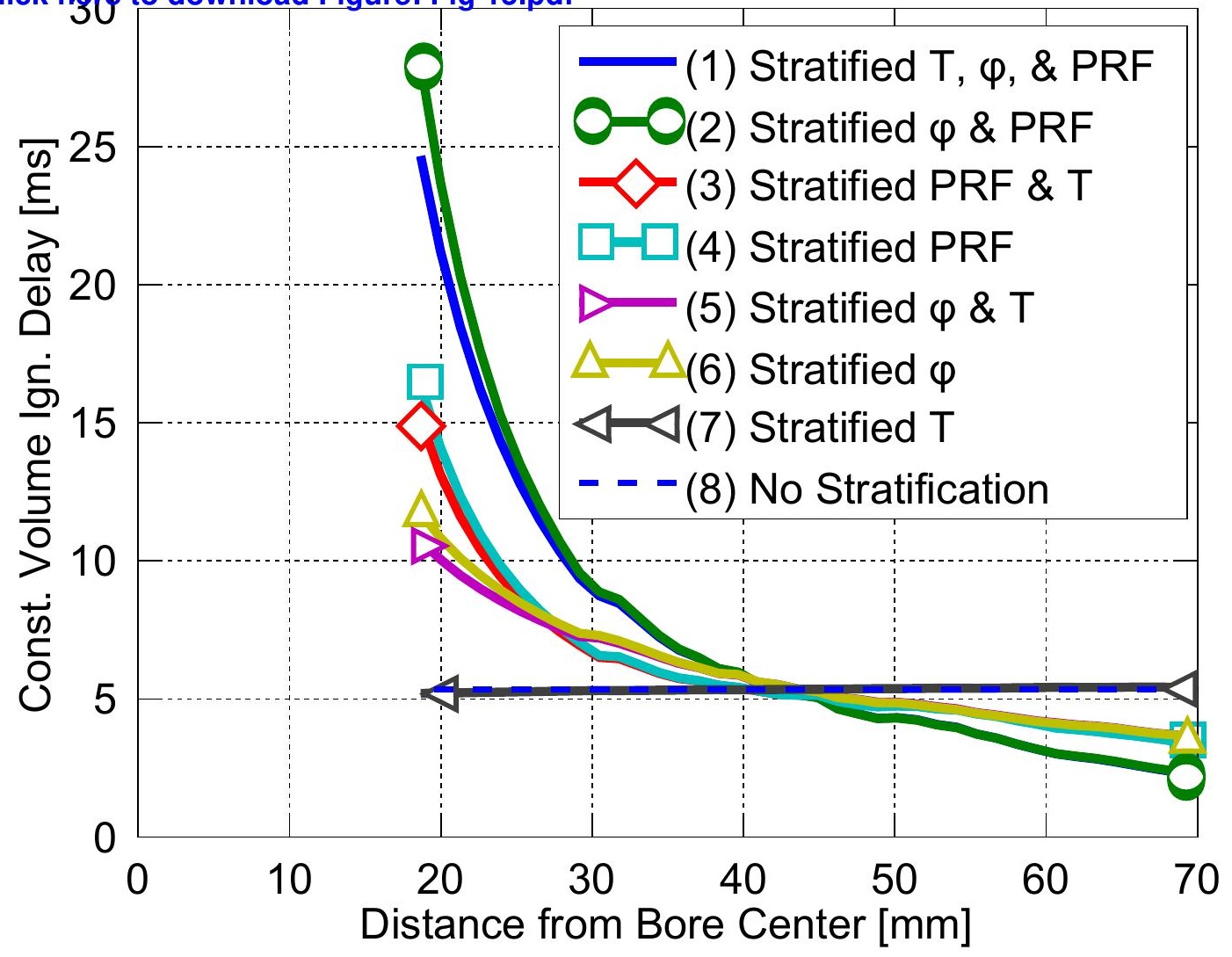


Figure 16

Click heg to download Figure: Fig 16.pdf

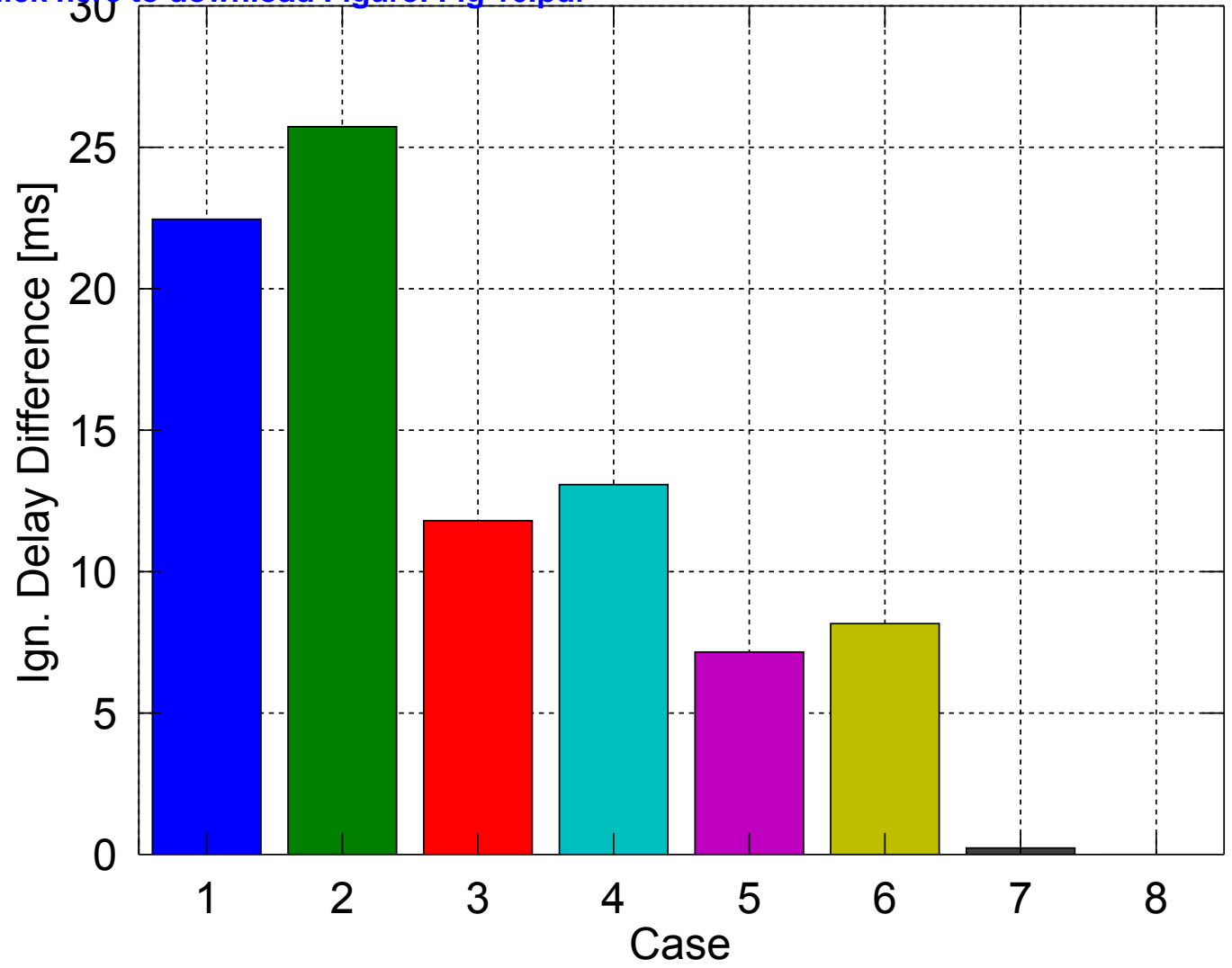


Figure 17

Click . .5 e to downloadd Fiqure: Fia 17.pdf

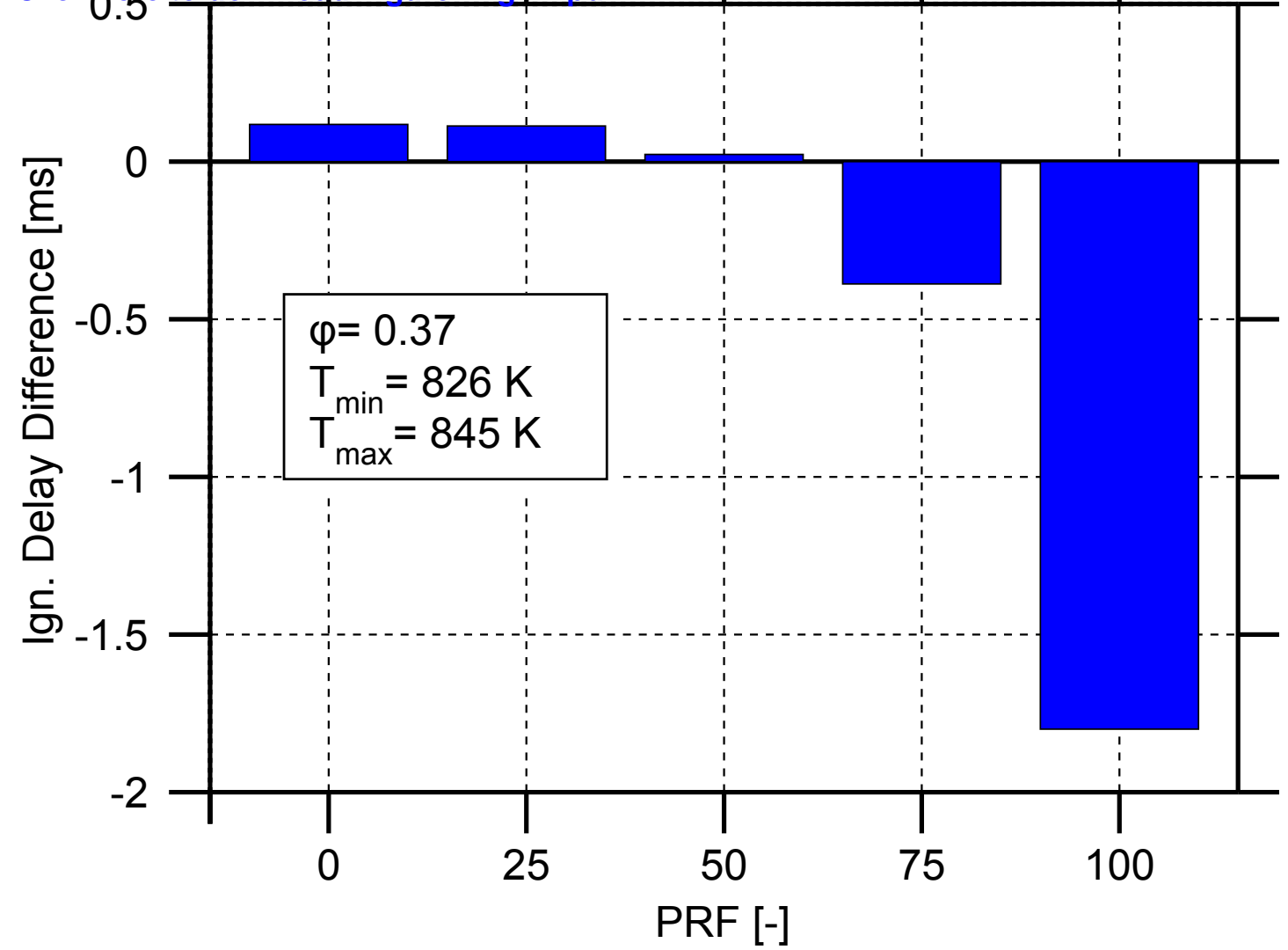


Figure 18

Click here to download hiqure: Fiq 16.pdf

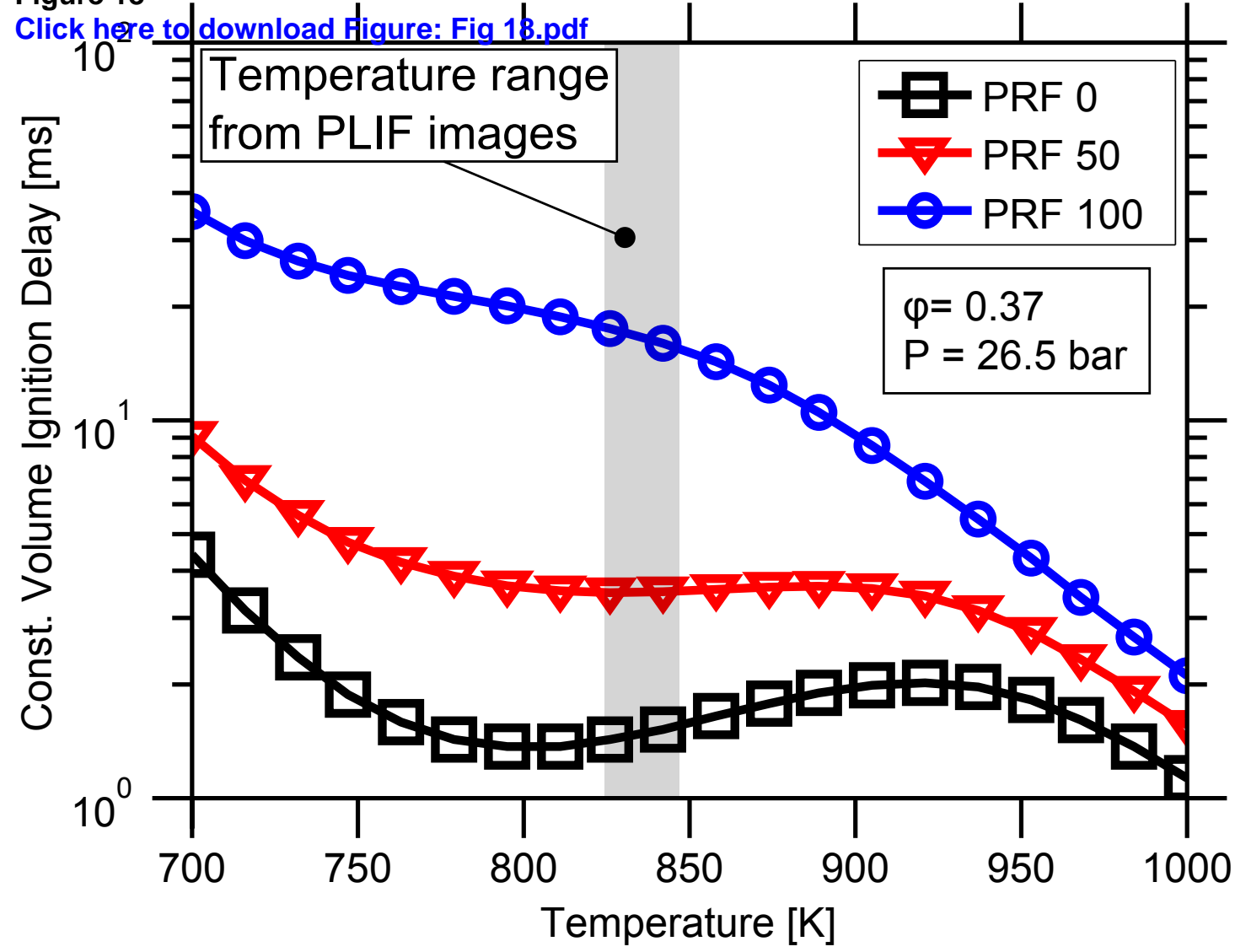

